\title{
An Investigation To Achieve a Good Surface Integrity in WEDM of Ti- 6242 Super Alloy
}

\section{Sonia Ezeddini}

Supmeca Institute of Mechanics of Paris

Wajdi Rajhi ( $\nabla$ wajdirajhi@gmail.com )

University of Hail

Mohamed Boujelbene

Supmeca Institute of Mechanics of Paris

\section{Emin Bayraktar}

Supmeca Institute of Mechanics of Paris

\section{Sahbi Ben Salem}

3University of Tunis El Manar

\section{Research Article}

Keywords: Wire electrical discharge machining (WEDM), Ti-6242 super alloy, signal-to-noise ratio (S/N), surface roughness (Ra), machining-induced surface damage

Posted Date: October 1st, 2021

DOl: https://doi.org/10.21203/rs.3.rs-925898/v1

License: () (i) This work is licensed under a Creative Commons Attribution 4.0 International License. Read Full License 


\section{Abstract}

Ti-6242 is a super alloy which exhibits the best creep resistance among available titanium alloys and is widely used in the manufacture by WEDM of aircraft engine turbomachinery components. However, the final quality of wire EDMed surface is a great challenge as it is affected by various factors that need optimization for surface integrity and machine efficiency improvement. The aim of this study is to investigate the effect of a set of cutting process parameters such as pulse on time $\left(T_{\text {on }}\right)$, servo voltage $(U)$, feed rate $(S)$ and flushing pressure $(p)$ on surface roughness $(S R)$ when machining Ti-6242 super alloy by WEDM process using a brass tool electrode and deionized water as a dielectric fluid. WEDM experiments were conducted, and $S R(R a)$ measurement was carried out using a 3D optical surface roughness-meter (3D-SurfaScan). As a tool to optimize cutting parameters for $S R$ improvement, Taguchi's signal-to-noise ratio $(S / M)$ approach was applied using $L_{9}\left(3^{\wedge} 4\right)$ orthogonal array and Lower-The-Better (LTB) criteria. Substantially, the findings from current investigation suggest the application of the values $0.9 \mu \mathrm{s}, 100 \mathrm{~V}, 29 \mathrm{~mm} / \mathrm{min}$, and 60 bar for $T_{\text {on }}, U, S$ and $p$ cutting parameters, respectively, for producing a good surface finish quality. Percent contributions of the machining parameters on $S R(R a)$ assessed based on ANOVA analysis are $62.94 \%, 20.84 \%, 11.46 \%$ and $4.74 \%$ for $U, S, T_{\text {on }}$ and $p$, respectively. Subsequently, accurate predictive model for $\mathrm{SR}(R a)$ is established based on response surface analysis (RSA). The contour plots for $S R(R a)$ indicate that when flushing pressure $p$ converges to a critical value (80 bar), a poor-quality surface finish is highly expected with the excessive increase in $U$ and $S$. Electron microscope scanning (SEM) observations have been performed on machined surface for a wide range of cutting parameters to characterize wire EDMed surface of Ti-6242. SEM micrographs indicate that the machined surface acquires a foamy structure and shows white layer and machining-induced damage that the characteristics are highly dependent on cutting parameters. At high servo-voltage, the decrease in pulse on time $T_{\text {on }}$ and feed rate $S$ results in a large decrease in overall machining-induced surface damage. Moreover, for high servo-voltage and feed rate levels, it has been observed that pulse on time could play a role of controlling the surface microcracks density. In fact, the use of a low pulse duration of cut combined with high servo-voltage and feed rate has been shown to inhibit surface microcracks formation giving the material surface a better resistance to cracking than at high pulse duration.

\section{Introduction}

One of the very plentiful metallic material on World, titanium is just lately employed in manufacturing, since an effective industrialization way was established just in the mid-twentieth century. Nowadays, titanium is extensively exploited in aerospace industry owing to its good mechanical and chemical properties mainly its high strength and good corrosion resistance, along with lightness (density of about $50 \%$ less than steel). The airplane engines aeronautic components made of titanium alloy may operate at low to rationally elevated temperatures [1]. The greatest advantage compared to aluminum alloys that are also characterized by their low density, lies in operating temperature of the titanium alloys components which may reach very high levels, close to $600{ }^{\circ} \mathrm{C}$, depending on the alloying elements [2]

Despite the relevant mechanical and chemical properties of titanium alloys, the machinability constitutes a great disadvantage and categorized as being poor. Therefrom, the complexity of conventional machining of titanium alloy parts which requires an extensive process time along with present high tool cost [3].

In the aerospace industry, some difficulties are encountered in manufacturing of the monolithic parts. Indeed, most commonly used materials are heat-resistant materials such as Ti-based alloy (6242) and nickel or cobalt based super alloys [4].

However, during the last 10 years, research and development R\&D on other machining technologies of titanium alloys has included both conventional and non-conventional methods of material processing involving abrasive water jet cutting, electrochemical/electrolytic point grinding (ECPG), abrasive methods such as cup grinding, new configurations of form milling including both indexable solid and tooling, laser cutting, and remarkably electrical discharge machining (EDM) [5-11].

The EDM process is a non-contact manufacturing process which occurs between workpiece and electrode tool separated by a stream of insulating dielectric fluid, which can generate material removal mainly by erosion phenomena regardless of the thermo-mechanical properties of the workpiece material. The eroded material portion which is not really removed and resolidified on the machined surface forms a superficial layer, so-called white layer, displaying distinct mechanical properties than original base material [12]. However, phenomenon involved in EDM process and achieved surface integrity have been traditionally challenged and researchers still debate on some aspects [13]. The surface alterations generated by EDM process have an important influence on surface integrity as stated in several studies [12-15]. Hence the importance of optimizing the whole of the factors involved in EDM process namely, the type of EDM process (WEDM or SEDM), the job and electrode tool materials, the machinery parameters, the characteristics of the employed dielectric liquid along with material removal rate MRR, kerf size, wire failure and wire wear rate frequency, cutting rate etc. to limit the time of machining and cost, and increasing productivity while guaranteeing good finish quality of the products machined surface [16-21].Among 
the titanium alloys used in manufacturing industries, we find the heat resistant Ti-6442 super alloy. The applications include aeronautical industries in particular turbines blades, parts of precision racing engine, the discs of hot section gas turbine parts, impellers, engine valves.

As being a super alloy, the machining of Ti-6442 by conventional processing techniques is difficult, hence the need for un-conventional process such as the EDM. Despite the implication of Ti-6242 super alloy in large industrial applications such as mentioned above and despite the significative influence of surface quality or roughness of EDMed components on efficiency of the machines [22], the study of the effect of process parameters in EDM process of this titanium alloy for the purpose of process optimization and surface quality improvement has been established by few studies. It has been observed from the exhaustive literature review that most of the investigations in EDM process of Ti-6242 super alloy has focused on the optimization of quality characteristics such as material removal rate MRR, over cut, tool wear rate and surface roughness as representing important indicators for machined surface quality and to assess the effectiveness of the process. Perumal et al. (2020) [23] studied the effect of discharge current, spark on time and tool diameter on MRR, over cut and tool wear rate in EDM of Ti-6242. In an earlier study, Perumal et al. (2019) [18] have analyzed statistically, for the same grade of titanium, the surface roughness and used SEM analysis to characterize surface integrity in terms of microstructure and surface cracks.

On the other hand, some works have investigated the WEDM of Ti-6242. Recently, Shather et al. (2021) [24] have investigated the nano dielectric effect in WEDM of Ti-6242 to improve process efficiency in particular increasing the MRR. Prasanna et al (2021) [25] have studied the effect of some WEDM process inputs mainly pulse on time, voltage, and wire feed rate on MRR and surface integrity of Ti6242. The obtained results show that surface roughness is highly affected by wire feed rate and voltage, and the MRR in WEDM of Ti6242 is improved when the pulse on time is increased. In a recent work, Perumal et al. [26] have machined the Ti-6242 by WEDM process to study the effect of pulse on-time, pulse off time, wire feed and wire tension on MRR and surface roughness. Accordingly, various approaches have been employed for predicting and optimizing process parameters in EDM and WEDM of Ti-6242. These approaches are based on the notion of metal machining, design of experiment (DOE) method, Taguchi method and the response surface methodology approach (RSA) [19,23,25- 29]. For instance, to improve the MRR and reduce the over cut and tool wear rate in EDM of Ti-6242, Taguchi based grey relational analysis method using L27 orthogonal array with multi response optimization has been used by Perumal et al. (2020) [23]. Taguchi method was employed by Prasanna et al (2021) [25] to identify optimal parameter combination for attaining minimal surface roughness in WEDM of Ti-6242. Even though being a material with very strong implication in industrial applications, the investigation of the surface roughness and the influencing setting parameters in WEDM of Ti-6242 super alloy has been presented by few studies and resultantly captured little interest. Apart from a few studies dealing with surface integrity optimization in WEDM of Ti-6242 such those indicated above, most of the researchers investigated only micro-structure and mechanical properties.

In this study, an attempt was made to manufacture the Ti-6242 titanium super alloy by WEDM using a brass tool electrode and deionized water as dielectric fluid to study the influence of setting parameters of primary noteworthiness such as pulse on time ( $\left.T_{\text {on }}\right)$, servo voltage $(U)$, feed rate $(S)$ and flushing pressure $(p)$ on machined surface quality. Accordingly, Taguchi's signal-to-noise ratio approach is employed to create plan for assessment of surface roughness considering the involved cutting settings input. Subsequently, SEM micrographs of machined surface obtained for various cutting settings are taken to examine microstructural alterations and surface damage characteristics in WEDM processing of the Ti-6242 super alloy. Thus, effect of cutting parameters on surface integrity has been deeply discussed.

\section{Experiment}

\section{1. Workpiece material and machining}

The material investigated in present work is the Ti-6242 titanium alloy. This material is an alpha-beta titanium alloy; it exhibits good mechanical strength and offers a sufficiently high creep resistance to temperatures as high as $550^{\circ} \mathrm{C}$. Ti- 6242 titanium alloy also offers fair weldability and good corrosion resistance. The chemical compositions, thermo-mechanical proprieties and microstructure (asreceived) of the Ti-6242 super alloy are given in Table 1, 2 and Figure 1-a respectively.

Table 1. Chemical composition of Ti-6242 super alloy [18]

\begin{tabular}{lllllllllll} 
Element & $\mathrm{Ti}$ & $\mathrm{Al}$ & $\mathrm{Sn}$ & $\mathrm{Zr}$ & $\mathrm{Mo}$ & $\mathrm{Si}$ & $\mathrm{C}$ & $\mathrm{N}$ & $\mathrm{O}$ & $\mathrm{H}$ \\
\hline$\%$ & Base & 6.20 & 1.95 & 3.8 & 2.0 & 0.08 & 0.021 & 0.008 & 0.06 & 0.0016
\end{tabular}


Table 2. Thermal and mechanical properties of Ti-6242 super alloy and brass wire-rod material [17] [18][30]

\begin{tabular}{lll} 
Material proprieties & Ti-6242 & Cutting brass wire (CuZn37) \\
\hline Thermal conductivity $\left(\mathrm{W} \mathrm{m}^{-1} \mathrm{~K}^{-1}\right)$ & 7 & 159 \\
\hline Linear expansion coefficient $\left(1 \mathrm{C}^{-6} \mathrm{~K}^{-1}\right)$ & 7.7 & - \\
\hline Specific heat $\left(\mathrm{j} \mathrm{g}^{-1} \mathrm{~K}^{-1}\right)$ & 460 & 380 \\
\hline Melting point $\left({ }^{\circ} \mathrm{C}\right)$ & $1588-1716$ & 990 \\
\hline Electrical resistivity $(\mathrm{ohm} \mathrm{cm})$ & - & 4.7 \\
\hline Young's modulus $(\mathrm{GPA})$ & 114 & - \\
\hline Ultimate tensile strength $(\mathrm{MPA})$ & 1010 & 896 \\
\hline Yield strength $(\mathrm{MPA})$ & 990 & - \\
\hline Elongation at break $(\%)$ & 3 & - \\
\hline Hardness $(\mathrm{HV})$ & 333 & -
\end{tabular}

The machining of Ti-6242 super alloy is conducted on a (Robofil 190) CNC wire EDM machine (Figure 1 (b)). A 0.25mm brass wire-rod (see Table 2 for material properties) and deionized water are used as tool electrode and dielectric medium, respectively, in cutting by wire EDM of a Ti-6242 rectangular workpiece to several samples $\left(12 * 8 * 3 \mathrm{~mm}^{3}\right)$ according to experimental configuration illustrated in Figure 1 (c).

Surface integrity in WEDM of Ti-6242 super alloy is studied through the examination of surface roughness along with machining-induced damage for Ti-6242 manufactured samples according to the strategy described below.

\subsection{Strategy}

For improving the quality characteristics and surface integrity in WEDM of Ti-6242 super alloy, we propose in present study following the various steps of diagram of Figure 2 where Taguchi method is employed including all of Signal-to-Noise ratio (S/M) approach, analysis of variance (ANOVA) and response surface analysis (RSA). In this work, 3 sets of 4 cutting parameters that are servo voltage or tension ( $U$ : the minimum input voltage value), pulse on time $\left(T_{o n}\right)$, feed rate or advance speed $(S)$, and injection pressure or flushing pressure $(p)$ are considered. Flushing (injection) pressure usually allows avoiding any undesirable effect from contact between the cut surface and debris, resulting in a good surface finish quality. WEDM experiments that the setup is illustrated in schematic diagram of Figure 1-a are conducted to investigate the effect of the process variables involved on surface roughness $(R a)$ during WEDM of Ti-6242 titanium alloy (Figure 3). In fact, arithmetic surface roughness ( $R a$ ) as being the most significant constituent of the surface integrity is influenced by several machining factors and plays a crucial role on the efficiency of aerospace components such as for instance turbomachinery blades as reported by [22] [32]. Hence, the need of surface roughness (Ra) improvement based on optimization of the process input factors. The cutting parameters ranges level along with the initial values for the machining settings have been chosen in the manufacturer's manual suggested for the investigated grade of titanium alloy. In Table 3 are reported the control factors, their symbols and their designated ranges employed in present work.

Table 3: Machining settings used in the experiments 


\begin{tabular}{|lllll|}
\hline Parameter & Unit & \multicolumn{3}{l|}{ Level } \\
\cline { 3 - 5 } & & L1 & L2 & L3 \\
\hline Tension $(U)$ & Volts & 80 & 100 & 120 \\
\hline Pulse on time $\left(T_{\text {on }}\right)$ & $\mu$ s & 0,8 & 0,9 & 1 \\
\hline Wire feed $(S)$ & $\mathrm{mm} / \mathrm{min}$ & 29 & 36 & 43 \\
\hline Pressure $(p)$ & Bar & 60 & 80 & 100 \\
\hline
\end{tabular}

\subsection{Experimental design based on Taguchi method}

Taguchi method is known as a solid design technique used in many studies to minimize noise sensitivity for any process and product. In Taguchi method a smaller number of orthogonal experimental combinations should be applied to significantly improve the design efficiency. As mentioned above, some researchers have used the Taguchi method in WEDM of Ti-6242 to optimize input parameters for surface integrity improvement. For instance, Perumal et al. [26] have applied a Taguchi L27 design and established that pulse off time, current and pulse on-time are the important parameters for the material removal rate in WEDM of Ti-6242. However, in the Taguchi technique there are two basic tools namely, the orthogonal array network (OA) and the signal-to-noise ratio (S/M). To save time and cost of experiments, $\mathrm{OA}$ is applied in the Taguchi method. However, the $S / N$ ratio is employed to assess the quality characteristics deviation from the desired values, including the Higher-The-Better (HTB), Nominal-The-Better (NTB) and Smaller-The-Better (STB) criteria. In this study we aim to optimize the surface roughness $(R a)$ so that the most objective type of objective function: Smaller-The-Better (STB), is considered herein. The exact relationship between the $\mathrm{S} / \mathrm{N}$ ratio and the signal according to STB objective function is given by:

$$
\frac{S}{N}=-10 \log \left(\sum_{i=0}^{n}\left(1 / Y i^{2}\right) / n\right)
$$

where $\mathrm{n}$ is the number of experiments, and $Y_{i}$ is the value of the $R a$.

In this study the standard experimental model is based on Taguchi Method. Thereby, an orthogonal matrix $L 9\left(3^{\wedge} 4\right)$ (see Table 4$)$ described in GS peace [33], including a basic design involving four control factors namely startup voltage (U), pulse on time $\left(T_{\text {on }}\right)$, feed rate $(S)$ and flushing pressure $(p)$ with three levels each, is used. Using the levels combination for each control factor shown in Table 3, a total of nine experimental runs should be conducted (Table 4). In this work, the roughness $(R a)$ represents the only machining characteristic to be investigated based on Taguchi method. WEDM experiments on Ti-6242 were performed to examine the significance of the input factors $U, T_{\text {on }}, S$ and $P$ on surface roughness $(R a)$. The latter was assessed using a 3D optical surface roughness-meter (3DSurfaScan), and the examined area was $2 * 1 \mathrm{~mm}^{2}$. The final experimental results are stated in Table 4.

Table 4: Experimental design using L9 orthogonal array 


\begin{tabular}{|llllllll|}
\hline Exp. No. & \multicolumn{3}{l}{ Factor assignment } & \multicolumn{7}{c|}{$R a(\mu \mathrm{m})$} & $S /$ N Ratio $(\mathrm{db})$ & Means \\
\cline { 2 - 5 } & $\mathrm{U}(\mathrm{V})$ & $\mathrm{T}_{\text {on }}(\mu \mathrm{m})$ & $\mathrm{S}(\mathrm{mm} / \mathrm{min})$ & $\mathrm{P}(\mathrm{bar})$ & & & \\
\hline 1 & 80 & 0.8 & 29 & 60 & 2.97 & -6.84881 & 2.200 \\
\hline 2 & 80 & 0.9 & 36 & 80 & 2.00 & -6.02071 & 2.160 \\
\hline 3 & 80 & 1 & 43 & 100 & 1.5 & -10.4228 & 3.320 \\
\hline 4 & 100 & 0.8 & 36 & 100 & 2.19 & -6.27775 & 2.060 \\
\hline 5 & 100 & 0.9 & 43 & 60 & 2.58 & -6.52710 & 2.120 \\
\hline 6 & 100 & 1 & 29 & 80 & 1.95 & -7.12085 & 2.270 \\
\hline 7 & 120 & 0.8 & 43 & 80 & 2.43 & -14.4032 & 5.250 \\
\hline 8 & 120 & 0.9 & 29 & 100 & 1.14 & -9.54247 & 3 \\
\hline 9 & 120 & 1 & 36 & 60 & 2,03 & -11.7205 & 3.855 \\
\hline
\end{tabular}

\section{Results And Discussion}

Since it is always advantageous to minimize the surface roughness, the $S / N$ ratio was applied to determine the optimum cutting parameters for a good surface finish quality in WEDM of Ti-6242 titanium alloy. Accordingly, Minitab statistical software is employed in all the analysis plots and designs. The response tables for $S / N$ ratio and means on surface roughness of Ti-6242 titanium alloy are given in Tables 5 and 6 , respectively. In Figure 4 and 5 are plotted the main effects for $S / N$ ratio and means on surface roughness $(R a)$ versus all the input factors, respectively.

The Figures 4-a, b, c, and d demonstrate the influence of the four input factors $\left(U, T_{o n}\right.$, $S$ and $\left.P\right)$ on the mean $S / N$ ratios, respectively. It can be observed that the lines joining data points of different levels have different slopes for servo voltage $(\zeta)$, pulse on time $\left(T_{\text {on }}\right)$, feed rate $(S)$ and flushing pressure $(p)$ input factors. Hence, the levels influence differently the surface roughness. Table 5 and figure 4 are obtained according to STB criterion. The level with the greatest $S / N$ ratio is considered the optimal level of the machining parameters. The better combination of input factors can be now selected from graph of Figure 4 (see also Table 5 (smaller is best)). It can be observed that the best combination is formed by the levels $(L 2, L 2, L 1, L 1)$ for input factors $\left(U, T_{\text {on }}, S\right.$ and $\left.P\right)$, respectively. Therefore, the lowest surface roughness $(R a)$ is achieved at the values $100 \mathrm{~V}, 0.9 \mu \mathrm{s}, 29 \mathrm{~mm} / \mathrm{min}$ and 60 bar for $U, T_{\text {on }}$, $S$ and $p$, respectively in WEDM of Ti-6242 titanium alloy by brass wire and deionized water.

Table 5. Response Table for Signal to Noise Ratios (Smaller is better)

\begin{tabular}{|c|c|c|c|c|c|}
\hline \multirow[t]{2}{*}{ Control factor } & \multicolumn{3}{|c|}{ 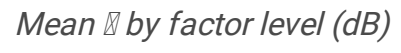 } & \multirow[t]{2}{*}{ Delta } & \multirow[t]{2}{*}{ Rank } \\
\hline & L1 & L2 & L3 & & \\
\hline$U(V)$ & -7.987 & -6.642 & -11.889 & 5.247 & 1 \\
\hline $\operatorname{Ton}(\mu s)$ & -9.177 & -7.586 & -9.755 & 2.168 & 3 \\
\hline$S(\mathrm{~mm} / \mathrm{min})$ & -7.837 & -8.229 & -10.451 & 2.614 & 2 \\
\hline$P($ bar $)$ & -8.365 & -9.405 & -8.748 & 1.039 & 4 \\
\hline
\end{tabular}

Response Table for Signal-to-noise

Figure 5-a shows that when the voltage $U$ increases from 80 to $100 \mathrm{~V}$, the mean of surface roughness $(R a)$ decreases slightly, however, the increase in servo voltage from 100 to $120 \mathrm{~V}$ results in significant rise in the mean of surface roughness. It can be seen also from the graph of Figure 5-c that mean of surface roughness increases at first with the increase in advanced speed $S$ from 29 to 36 , thereafter it leaps as $S$ rises from 36 to $43 \mathrm{~mm} / \mathrm{min}$.

On the other hand, it can be observed from Table 6 that the effect of machining parameters $U$ and $S$ on mean of surface roughness $(R a)$ in WEDM of Ti-6242 alloy using brass wire and deionized water dominates the effect of $T_{\text {on }}$ and $P$. Indeed, the higher the slope values in 
the main effects plot, the higher the values of delta in the response table for means. The rank directly represents the level of input factor effect based on the values of delta. Herein, the effects of various input factors (according to the ranks of response tables given in Tables 5 and 6 ) in sequence of their effect on $R a$ are servo voltage $U$, feed rate $S$, pulse on time $T_{o n}$, and flushing pressure $p$. This means that flushing pressure $p$ affects the $R a$ at lowest level, however, servo voltage $U$ affects it at highest level.

Table 6: Response Table for Means

\begin{tabular}{|llllll|}
\hline \multirow{2}{*}{ Control factor } & \multicolumn{3}{l}{ Mean factor level } & Delta & Rank \\
\cline { 2 - 5 } & $L 1$ & $L 2$ & $L 3$ & & \\
\hline$U(V)$ & 2,560 & 2,150 & 4,035 & 1,885 & 1 \\
\hline$T_{\text {on }}(\mu s)$ & 3,170 & 2,427 & 3,148 & 0,743 & 3 \\
\hline$S(\mathrm{~mm} / \mathrm{min})$ & 2,490 & 2,692 & 3,563 & 1,073 & 2 \\
\hline$P($ bar $)$ & 2,725 & 3,227 & 2,793 & 0,502 & 4 \\
\hline
\end{tabular}

\subsection{Analysis of variance (ANOVA)}

\subsubsection{ANOVA for surface roughness $R a$}

Hereafter, analysis of variance (ANOVA) is performed to assess the contribution of different input factors $\left(U, T_{\text {on }}, S\right.$, and $P$ ) on response variable $R$. Table 7 shows the analysis results by ANOVA which approves that machining voltage $U$, injection pressure $p$, wire feed rate $S$ and pulse on time $T_{\text {on }}$ are significant machining settings for surface roughness $R a$ because their P-value is less than 0.05 . Larger F-Value signifies that the variation of the machining setting $\left(U, S, T_{\text {on }}\right.$ and $\left.P\right)$ results in a significant variation in the machining characteristics $(R a)$.

According to $F_{\text {test }}$ analysis, it can be confirmed that the highly significant parameters in deceasing order in terms of the effect on surface roughness $(R a)$ are servo voltage $U$, feed rate $S$, pulse on time $T_{\text {on }}$ and flushing pressure $p$. However, the percent contributions of the machining parameters on $R a$ are shown in table 7 and figure 6. Startup voltage $U$ is found to be major factor affecting the $R a$ ( $62.94 \%)$, the percent contribution of feed rate $S$, pulse on time $T_{\text {on }}$, and flushing pressure $p$ on the $R a$ are $20.84 \%, 11.46 \%$, and $4.74 \%$ respectively.

Table 7: Results of ANOVA for Ra

\begin{tabular}{|llllllll|}
\hline Process parameter & DF & Seq SS & Adj SS & Adj MS & F-value & P-value & Contribution \% \\
\hline U & 2 & 11.7939 & 11.7939 & 5.89695 & 11413.45 & 0.000 & 62.94 \\
\hline Ton & 2 & 2.1476 & 2.1476 & 1.07382 & 2078.35 & 0.000 & 11.46 \\
\hline S & 2 & 3.9050 & 3.9050 & 1.95252 & 3779.06 & 0.000 & 20.84 \\
\hline P & 2 & 0.8882 & 0.8882 & 0.44412 & 859.58 & 0.000 & 4.74 \\
\hline Error & 9 & 0.0046 & 0.0046 & 0.00052 & & & 0.02 \\
\hline Total & 17 & 18.7394 & & & & & 100.00 \\
\hline S & R-sq & R-sq(adj) & R-sq(pred) & & & & \\
\hline 0.0227303 & $99.98 \%$ & $99.95 \%$ & $99.90 \%$ & & & & \\
\hline
\end{tabular}

\subsubsection{ANOVA for regression model of $R a$}

In Figure 7 are presented the residual plots for surface roughness $(R a)$ using 18 experimental runs. We realized 9 experiments, but the roughness is tested twice for each experiment. The graphs of figure 7 demonstrates that residues found are independent while displaying a randomized dispersion. Moreover, Figure 7 shows that the variable follows the normal distribution, and the residuals are distributed 
roughly in a straight line, displaying a good relationship between the analytically predicted values for all Ra performances and experiment. The results presented in Table 8 are obtained with Minitab Software using ANOVA analysis. The percentage of variation in the response displayed in Table 8 is very high $(\mathrm{R}-\mathrm{sq}(\mathrm{adj})>99 \%)$, thereby, the model fits well the data.

Table 8: Result of ANOVA for Regression model of Ra

\begin{tabular}{|llllllll|}
\hline Source Regression & DF & Seq SS & Adj SS & Adj MS & F-Value & P-Value & Contribution $\%$ \\
\hline Regression & 8 & 18.7348 & 18.7348 & 2.34185 & 4532.61 & 0.000 & $99.98 \%$ \\
\hline $\mathrm{U}$ & 1 & 6.5269 & 4.5964 & 4.59643 & 8896.33 & 0.000 & 34.83 \\
\hline $\mathrm{T}_{\text {on }}$ & 1 & 0.0014 & 2.1475 & 2.14754 & 4156.54 & 0.000 & 0.01 \\
\hline $\mathrm{S}$ & 1 & 3.4561 & 0.3190 & 0.31895 & 617.33 & 0.000 & 18.44 \\
\hline $\mathrm{P}$ & 1 & 0.0140 & 0.8857 & 0.88566 & 1714.18 & 0.000 & 0.07 \\
$\mathrm{U}^{2}$ & 1 & 5.2670 & 5.2670 & 5.26702 & 10194.24 & 0.000 & 28.11 \\
\hline $\mathrm{T}^{2}{ }_{\text {on }}$ & 1 & 2.1462 & 2.1462 & 2.14623 & 4153.98 & 0.000 & 11.45 \\
\hline $\mathrm{S}^{2}$ & 1 & 0.4489 & 0.4489 & 0.44890 & 868.84 & 0.000 & 2.40 \\
\hline $\mathrm{P}^{2}$ & 1 & 0.8742 & 0.8742 & 0.87423 & 1692.05 & 0.000 & 4.67 \\
\hline Error & 9 & 0.0046 & 0.0046 & 0.00052 & & & 0.02 \\
\hline Total & 17 & 18.7394 & & & & & 100.00 \\
\hline $\mathrm{S}$ & $\mathrm{R}-\mathrm{sq}$ & $\mathrm{R}$-sq(adj) & $\mathrm{R}$-sq(pred) & & & & \\
\hline 0.0227303 & $99.98 \%$ & $99.95 \%$ & $99.90 \%$ & & & & \\
\hline
\end{tabular}

The quadratic model proposed to predict surface roughness $(R a)$ can be expressed based on response surface analysis (RSA) as a function of $U, T_{\text {on }}, S$ and $P$ in regression Equation (2):

\section{$R a=84,66-0,53687 U-131,96$ Ton $-0,4156 S+0,18871 P+0,002869 U^{2}$ $+73,25$ Ton $^{2}+0,006837 S^{2}-0,001169 P^{2}(2)$}

Figure 8 shows a contrast between surface roughness Ra measured experimentally and predicted analytically based on the model equation Eq.2. It can be seen that the forecasted values of $R a$ are very close to experiment, thereby, highly promising the model described by Equation 2 in predicting the surface roughness $(R a)$ in WEDM of Ti-6242 using brass wire and deionized water.

Figures 9 a, b, c, d, e and f show the contour plots for surface roughness Ra: $S$ vs $p, T_{\text {on }}$ vs $p, T_{\text {on }}$ vs $S, U v s p, U v s S$ and $U v s T_{\text {on }}$ respectively. It's clear that the dark blue zone of each graph represents the optimal cutting parameters ensuring a good surface finish quality. Figure 9-a shows that the increase in flushing pressure had not significant effect on surface roughness for minimal feed rate values. However, when flushing pressure converges to $80 \mathrm{bar}$, the excessive increase in feed rate $S$ results in the highest surface roughness. Once more, if this critical value of flushing pressure is reached for lower values of pulse on time, the surface finish quality decreases significantly (Figure 9-b). Figure 9-c indicates that the excessive increase in servo voltage $U$ results in a bad surface finish quality practically regardless the amount of flushing pressure $p$ (for $p$ less than 96 bar). But, for extreme values of servo voltage $U$, surface roughness reaches its maximum again when flushing pressure converges to 80 bar.

Hence, it can be concluded that to obtain good surface finish the value 80 bar of flushing pressure should be avoided for highest amounts of servo voltage $U$ and feed rate $S$ along with for lower levels of pulse on time $T_{\text {on }}$. In fact, this finding could be supported by Figure 4-d which demonstrates that the mean $S / N$ ratio goes down and achieves a minimum at the flushing pressure of 80 bar. However, at the same level of flushing pressure, surface roughness mean was the highest predicted as given in Figure 5-d. 
Moreover, it can be observed from Figures 9-d and 9-e that a very poor surface roughness is highly expected with excessive decrease in pulse on time $T_{\text {on }}$ if attended by an important increase in each of servo voltage and feed rate. Finally, Figure 9-f demonstrates that the extreme surface roughness or rougher machined surface are obtained for a greater feed rate $S$ and a higher servo voltage $U$.

\section{Effect Of Cutting Parameters On Machined Surface Characteristics}

\section{4-1-SEM examination of white layer}

Service lifetime of a wire EDMed component depends chiefly on surface integrity. The latter is characterized by the microstructural alterations on the machined surface and sublayers regions (the presence of white layer), surface roughness, surface damage formation, hardness distribution, residual stresses, etc. However, the low thermal conductivity that characterizes titanium alloys makes it crucial to study the effect of the WEDM process and the machining parameters that influence it on surface integrity, in particular surface roughness and crack formation, as reported by [16] in the EDM of the titanium alloy Ti6AI4V. The surface roughness in EDM has been defined in [16] as a process of chip forming which takes place on surface of wire EDMed component and manifested by the presence of spherical debris particles. It has been also reported in the same investigation that crater size along with machining-induced cracks could be important factors on which the roughness of the machined surface depends. Hereafter, type of surface integrity of Ti-6242 wire EDMed samples is analyzed using SEM micrograph. The aim was to assess the effect of machining parameters on surface characteristics such as white layer thickness and surface damage density. The combinations set studied below are taken from Table 4 and completed with further cutting experiments so that the flushing pressure is fixed at 100 bar. Cross sectional microstructure of the machined surface of Ti-6242 titanium alloy observed under SEM for two different sets of machining parameters is given in Figure 10. The latter shows signs typical of the material that has experienced important metallurgical alterations as it was entirely melted and was then cooled down rapidly during processing by WEDM.

Figure 10 shows the presence of a recast layer (white layer), characterized by hexagonal martensitic structure in WEDM of Ti-6242 super alloy, as a result of re-solidification of molten metal residual portion that had not flushed away by dielectric liquid and had not experienced any hydrodynamic effect during bubble collapsing phase. Moreover, it is evident that the machined surface is covered with a white layer of varying thickness and contains microcracks and pores. Figure 10 also shows that tempered layer formed by the sublayers that have not melted by the heat produced during WEDM processing is characterized by important microstructural alterations. In fact, tempered layer is composed by larger and elongated grains as indicated in Figure $10 \mathrm{a}$ and $\mathrm{b}$. Coarser grain size is the result of recrystallization process at elevated temperatures inside a slight tempered layer that the thickness is of about $15 \mu \mathrm{m}$ and does not exceed $10 \mu \mathrm{m}$ for the sets 1 and 2 of machining parameters as given in Figures $10 \mathrm{a}$ and $\mathrm{b}$, respectively. A slight tempered layer in WEDM of Ti6242 super alloy is well expected due to the low thermal conductivity of titanium alloys. Material microstructure of the region located below tempered layer remains unaffected by heat generated during WEDM process. This region preserves small grains size character and is considered part of base material. However, the thickness of white layer and the surface cracking generation are highly influenced by machining parameters. Figure 10 shows that the increase in servo-voltage from 80 to $120 \mathrm{~V}$ and the decrease in pulse on time from 1 to $0.8 \mu$ s result in a thinner white layer as the thickness of that layer has decreased from 27 to $10 \mu \mathrm{m}$. Indeed, the decrease in pulse on time results in a decrease in MRR because spark intensity is low, and due to low material conductivity, the amount of material removed from the machined surface is less, resulting in a small amount of resolidified material and a thin recast layer. Moreover, set 2 of machining parameters is characterized by a high flushing pressure, which also could lead to a thin white layer. Figure 10 shows that surface microcracks extend arbitrarily to various depths and majority of observed microcracks are found to grow towards the bulk material. Indeed, the state of residual stresses built-up within the machined surface is governed by plane tensile stresses that accumulate parallel to surface and result in microcracks normal to white layer of hard hexagonal martensitic structure. Majority of microcracks in the white layer developed using set 1 of machining parameters are deep and penetrate into the tempered layer. However, the decrease in pulse on time leads to the generation of shallow microcracks in machined surface. It can be seen also from Figure 10 that higher the pulse on time thicker the white layer, and wider and deeper the microcracks inside the machined surface. The reverse is also true.

\section{4-2-SEM examination of machining-induced damage}

SEM examination of machined surface topography has been carried out for wire EDM of Ti-6242 super alloy with respect to various combination sets of machining parameters $\left(V, S, T_{\text {on }}, p\right)$ taken from Table 3.

Figures 11 and 12 (a, b, c, d) show some SEM micrographs of Ti-6242 wire EDMed surface of samples processed in deionized water using a brass tool electrode. So, four combinations of machining parameters are selected in the investigation of surface characteristics 
of Ti-6242 super alloy in WEDM process. Each combination set is associated with the corresponding machined surface SEM micrograph via Table 9.

Figure 11 shows a typical SEM micrograph of wire EDMed surface produced by the combination set 1 of machining parameters: highest levels of servo-volatge and pulse on time, medium levels of feed rate and flushing pressure according to Table 3. From SEM micrograph of Figure 11, it is obvious that machined surface reveals porous and foamy structure caused by dynamic gas bubble formation during machining. It can be also seen from Figure 11 that the machined surface is made up of droplet shaped resolidified material with randomly distribution of many spark-induced craters with varying size, many spherical debris, huge number of microvoids and pockmarks, and marked by the presence of surface microcracks network to form a rough surface. The effect of wire EDM cutting parameters on surface damage characteristics could be explained based on the comparison of Figures 12 (a, b, $c, d$ ) in terms of the density and widens of surface microcracks along with craters size and microvoids density. The results of such a comparison are reported in Table 10.

Table 9: Combination sets of WEDM cutting settings for SEM examination of surface damage characteristics

\begin{tabular}{|c|c|c|c|c|}
\hline \multirow{2}{*}{$\begin{array}{l}\text { Cutting } \\
\text { parameter }\end{array}$} & \multicolumn{4}{|l|}{ Combinations sets } \\
\hline & $\begin{array}{l}\text { Set } 1 \text { (micrograph of } \\
\text { figure 9-a) }\end{array}$ & $\begin{array}{l}\text { Set } 2 \text { (micrograph of } \\
\text { figure } 9-b)\end{array}$ & $\begin{array}{l}\text { Set } 3 \text { (micrograph of } \\
\text { figure 9-c) }\end{array}$ & $\begin{array}{l}\text { Set } 4 \text { (micrograph of } \\
\text { figure 9-d) }\end{array}$ \\
\hline Tension $(U)$ & 120 & 120 & 100 & 120 \\
\hline $\begin{array}{l}\text { Pulse on time } \\
\left(T_{\text {on }}\right)\end{array}$ & 1 & 0.9 & 0.9 & 0.8 \\
\hline Wire feed $(S)$ & 36 & 29 & 43 & 43 \\
\hline Pressure (p) & 100 & 100 & 100 & 100 \\
\hline
\end{tabular}

Table 10: Effect of WEDM machining parameters evolution on surface damage characteristics

\begin{tabular}{|c|c|c|c|c|c|c|c|c|c|c|c|c|c|c|c|c|c|c|}
\hline \multirow{2}{*}{$\begin{array}{l}\text { Sets } \\
\text { Parameters }\end{array}$} & \multicolumn{3}{|c|}{ From 1 to 2} & \multicolumn{3}{|c|}{ From 1 to 3} & \multicolumn{3}{|c|}{ From 1 to 4} & \multicolumn{3}{|c|}{ From 2 to 3} & \multicolumn{3}{|c|}{ From 2 to 4} & \multicolumn{3}{|c|}{ From 4 to 3} \\
\hline & $U$ & $T_{\text {on }}$ & $S$ & $U$ & $T_{o n}$ & $S$ & $U$ & $T_{\text {on }}$ & $S$ & $U$ & $T_{\text {on }}$ & $S$ & $U$ & $T_{\text {on }}$ & $S$ & $U$ & $T_{o n}$ & $S$ \\
\hline Variation & $120 \mathrm{~V}$ & $\downarrow$ & $\downarrow$ & $\downarrow$ & $\downarrow$ & $\uparrow$ & $120 \mathrm{~V}$ & $\downarrow \downarrow$ & $\uparrow$ & $\downarrow$ & $\begin{array}{l}0.9 \\
\mu s\end{array}$ & $\uparrow \uparrow$ & $120 \mathrm{~V}$ & $\downarrow$ & $\uparrow \uparrow$ & $\downarrow$ & $\uparrow$ & $43 \mathrm{~mm} / \mathrm{min}$ \\
\hline $\begin{array}{l}\text { Cracks } \\
\text { density }\end{array}$ & $\begin{array}{l}-- \\
\text { (Drop) }\end{array}$ & & & + & & & -- & & & ++ & & & $\approx$ & & & + & & \\
\hline $\begin{array}{l}\text { Cracks } \\
\text { widens }\end{array}$ & -- & & & $\approx$ & & & + & & & + & & & ++ & & & - & & \\
\hline $\begin{array}{l}\text { Crater } \\
\text { size }\end{array}$ & -- & & & + & & & $\approx$ & & & ++ & & & ++ & & & $\approx$ & & \\
\hline $\begin{array}{l}\text { Microvoids } \\
\text { density }\end{array}$ & -- & & & + & & & - & & & ++ & & & + & & & + & & \\
\hline
\end{tabular}

It can be seen from Table 10 that at the same servo-voltage (120V), the decrease in pulse on time $T_{\text {on }}$ and feed rate $S$ results in a large decrease in surface damage (Figures $12 \mathrm{a}$ and $\mathrm{b}$ ). On the other hand, for a high fixed feed rate $(43 \mathrm{~mm} / \mathrm{min})$, microcracks have been shown to be denser but narrower with the increase in pulse on time and reduction in servo-voltage (Figures $12 \mathrm{~d}$ and $\mathrm{c}$ ). Moreover, at a high fixed level of servo-voltage, microcracks are getting wider with the large increase in feed rate (Figures $12 \mathrm{~b}$ and $\mathrm{d}$ ). At the same pulse on time, the excessive increase in feed rate $S$ up to $43 \mathrm{~mm} / \mathrm{min}$ results in an increase in crater size and microvoids density. In addition, such cutting conditions have made of shallow and sub microcracks deeper, denser and wider rendering machined surface roughness more pronounced (Figures b and c). It can be also deduced from Table 10 that pulse on time has a significant effect on surface cracking 
density in accordance with the observations reported in [16]. By decreasing in pulse on time from 1 to $0.8 \mu$ s and keeping servo-voltage constant at $120 \mathrm{~V}$, the density of surface microcracks decreases significantly (Figures 12 a and d).

In Figure 13 is illustrated a histogram in which the variation of surface damage with machining parameters is quantified in terms of surface microcracks density $(\eta)$. In Figure 13 a fifth combination set of machining parameters has been included. Graph of figure 13 (combination sets 1 and 3 ) shows that for high feed rate and servo-voltage levels, surface cracks densities are high ( $\eta=13.8$ and 36.2 $\mu \mathrm{m} / \mu \mathrm{m}^{2}$ ) for relatively high levels of pulse on time $T_{\text {on }}$. However, set combination 4 proves that the excessive increase in servo-voltage and feed rate cannot cause high microcracks density unless a high pulse on time is applied to cutting process. Hence, it can be concluded that for high servo-voltage and feed rate levels, pulse on time plays a critical role in promoting or inhibiting surface microcracks formation and could control surface microcracks density.

On the other hand, Figure 13 indicates that servo voltage does not exhibit an interpretable effect on surface cracking density for the levels of voltage ranging between 100 and $120 \mathrm{~V}$. However, it has been found that further decrease in servo-voltage to $80 \mathrm{~V}$ is marked by a significant decrease in surface microcracks density $\left(\eta=1.8 \mu \mathrm{m} / \mu \mathrm{m}^{2}\right)$ even for high levels of feed rate and pulse on time as demonstrated in combination set 5 of Figure 13. This result could be supported by the SEM micrograph of Figure 14.

\section{Conclusion}

The investigation of final surface quality in wire EDM of Ti-6242 titanium alloy using a brass tool electrode and deionized water as a dielectric fluid has been subject of the present work. The effect of WEDM process settings such as pulse on time $\left(T_{\text {on }}\right)$, servo voltage ( $\left.U\right)$, feed rate $(S)$ and flushing pressure $(p)$ on surface roughness $(R a)$ has been studied. Optimization of the implicated cutting parameters for surface quality improvement has been carried out based on Taguchi's signal-to-noise ratio $(S / M)$ approach. Accordingly, L9 (3^4) orthogonal array-based experimentation was designed, and Lower-The-Better (LTB) criteria was applied. Percent contributions of each machining parameter on SR $(R a)$ has been determined using ANOVA analysis, and a quadratic model expressed with $U, T_{\text {on }}, S$ and $P$ to predict SR $(R a)$ has been established using response surface analysis (RSA). SEM observations were performed to examine microstructural alterations and machining-induced surface-breaking cracks in wire EDMed surface of Ti-6242 super alloy. The effect of the involved machining parameters on white layer thickness and surface microcracks density has been discussed deeply. During this investigation it was established that:

- The lowest surface roughness $(R a)$ is achieved at the values $100 \mathrm{~V}, 0.9 \mu \mathrm{s}, 29 \mathrm{~mm} / \mathrm{min}$ and 60 bar for $U, T_{\text {on }}$, $S$ and $p$, respectively.

- Startup voltage $U$ was found to be the most important factor affecting the SR $(R a)$ with percent contribution of $62.94 \%$. The percent contribution of feed rate $S$, pulse on time $T_{\text {on }}$, and flushing pressure $p$ on $R a$ are $20.84 \%, 11.46 \%$, and $4.74 \%$ respectively.

- The predictive model of surface roughness is quite accurate and could be explored to forecast $(R a)$ in wire EDM of Ti-6242 titanium alloy.

- Contours plots revealed that the rougher Ti-6242 surface is obtained at high levels of servo-voltage $U$ and feed rate $S$ for critical flushing pressure $p$ close to 80 bar.

- SEM examination of machined surface demonstrated that white layer thickness and surface damage characteristics are highly dependent on cutting parameters.

- Even though there was great growth in servo-voltage $V$, the large decrease in pulse on time $T_{\text {on }}$ results in a decrease in white layer thickness with the generation of shallow microcracks.

- The decrease in pulse on time $T_{\text {on }}$ and feed rate $S$ results in a large decrease in overall machining-induced damage at high servovoltage $V$.

- Surface microcracks are getting wider (at a high fixed level of servo-voltage $V$ ) with the large increase in feed rate $S$.

- Pulse duration $T_{\text {on }}$ plays a role of regulating the surface microcracks density at high servo-voltage $V$ and feed rate $S$ levels.

- The lower surface microcracks density is achieved for lower servo-voltage $V$ even though pulse on time $T_{\text {on }}$ and feed rate $S$ are extreme.

\section{Declarations}

\section{Funding}


The author(s) disclosed receipt of the following financial support for the research, authorship, and/or publication of this article: This research has been funded by Scientific Research Deanship at University of Ha'il - Saudi Arabia through project number: RG-20 122.

\section{Conflicts of interest}

The authors of present manuscript declare that they have no conflict of interest.

Availability of data and material (Not applicable)

Code availability (Not applicable)

Ethics approval (Not applicable)

Consent to participate (Not applicable)

Consent for publication (Not applicable)

\section{References}

1. Metals Handbook TENTH EDITION Volume 2 Properties and Selection: Nonferrous Alloys and Special-Purpose Materials (1990). ASM International the Materials Information Society. ISBN: 978-0-87170-378-1.

2. Boyer RR (1996) An overview on the use of titanium in the aerospace industry. Materials Science and Engineering: A 213: 103-114. https://doi.org/10.1016/0921-5093(96)10233-1.

3. Kramer A, Lung D, Klocke F (2012) High performance cutting of aerospace materials. Adv.Mater,Res 498: 127-132. https://doi.org/10.4028/www.scientific.net/AMR.498.127.

4. Aspinwall DK, Soo, SL, Berrisford, AE, Walder, G (2008) Workpiece surface roughness and integrity after WEDM of Ti6Al-4V and Inconel 718 using minimum damage generator technology. Annals of CIRP 57: 187-190. https://doi.org/10.1016/j.cirp.2008.03.054.

5. Curtis DT, Soo SL, Aspinwall, DK, Huber C, Fuhlendorf J, Grimm A (2008) Production of complex blade mounting slots in turbine disks using novel machining techniques. Proceedings of the 3rd International Conference on High Performance Cutting - CIRP HPC. Dublin, Ireland, 219-228.

6. Boud F, Carpenter C, Folkes J, Shipway PH (2010) Abrasive waterjet cutting of a titanium alloy: The influence of abrasive morphology and mechanical properties on workpiece grit embedment and cut quality. J. Mater. Process. Technol. 210: 2197-2205. https://doi.org/10.1016/j.jmatprotec.2010.08.006.

7. Curtis DT, Soo SL, Aspinwall DK, Sage C (2009) Electrochemical superabrasive machining of a nickel-based aeroengine alloy using mounted grinding points. Annals of CIRP 58: 173-176. https://doi.org/10.1016/j.cirp.2009.03.074.

8. Kappmeyer G, Hubig C, Hardly M, Witty M, Brusch M (2012) Modern Machining of Advanced Aerospace Alloys - Enabler for Quality and Performance. Procedia CIRP 1: 28-43. https://doi.org/10.1016/j.procir.2012.04.005.

9. Meurig T, Sam T, Martin J (2010) Microstructural damage during high-speed milling of titanium alloys. Scripta Materialia $62,250-$ 253. https://doi.org/10.1016/j.scriptamat.2009.11.009.

10. Ezeddini S, Zambelis G, Bayraktar E, Miskioglu I, Katundi D (2018) Experimental Study of Laser Cutting Process of Titanium Aluminium (Ti-Al) Based Composites Designed Through Combined Method of Powder Metallurgy and Thixoforming. Mechanics of Composite and Multi-functional Materials 6: 21-27.https://www.springerprofessional.de/en/experimental-study-of-laser-cuttingprocess-of-titanium aluminiu/15210302

11. Evarasiddappa D, Chandrasekaran M, Arunachalam R (2020) Experimental investigation and parametric optimization for minimizing surface roughness during WEDM of Ti6Al4V alloy using modified TLBO algorithm. J Braz. Soc. Mech. Sci. Eng. 42, 128. https://doi.org/10.1007/s40430-020-2224-7.

12. Sidhom H, Farhat G, Tidiane A, Gonzalo G, Chedly B (2013) Effect of electro discharge machining (EDM) on the AISI316L SS white layer microstructure and corrosion resistance. The International Journal of Advanced Manufacturing Technology 65:141-153. https://doi.org/10.1007/s00170-012-4156-6.

13. Rajhi W, Alatawi I, Subhani T, Ayadi B, Al-Ghamdi A, Khaliq A (2021) A contribution to numerical prediction of surface damage and residual stresses on die-sinking EDM of Ti6Al4V. Journal of Manufacturing Processes 68:1458-1484, https://doi.org/10.1016/j.jmapro.2021.06.056. 
14. Zeid OA (1997) On the effect of electro discharge machining parameters on the fatigue life on AISID6 tool steel. J. Mater. Process. Technol. 68: 27-32. https://doi.org/10.1016/S0924-0136(96)02523-X.

15. Li L, Wei XT, Guo YB, Li W, Liu JF (2014) Surface Integrity of Inconel 718 by Wire-EDM at Different Energy Modes Journal of Materials Engineering and Performance. 23: 3051-3057. https://doi.org/10.1007/s11665-014-1048-y.

16. Hasçalık A, Çaydaş U (2007) Electrical discharge machining of titanium alloy (Ti-6Al-4V), Applied Surface Science 253: $9007-9016$. https://doi.org/10.1016/j.apsusc.2007.05.031.

17. Nourbakhsh F, Rajurkar KP, Malshe AP, Cao J (2013) Wire electro-discharge machining of titanium alloy. Procedia CIRP 5: 13-18. https://doi.org/10.1016/j.procir.2013.01.003.

18. Perumal A, Azhagurajan A, Baskaran S, Prithivirajan R, Narayansamy P (2019) Statistical evaluation and performance analysis of electrical discharge machining (EDM) characteristics of hard Ti-6Al-2Sn-4Zr-2Mo alloy. Materials Research Express 6. https://doi.org/10.1088/2053-1591/ab06da.

19. Ben Salem S, Tebni W, Bayraktar E (2011) Prediction of surface roughness by experimental design methodology in Electrical Discharge Machining (EDM). Journal of Achievements in Materials and Manufacturing Engineering 49:150-157. http://jamme.acmsse.h2.pl/papers_vol49_2/4923.pdf

20. Boujelbene M, Bayraktar E, Tebni W, Ben Salem S (2009) Influence of machining parameters on the surface integrity in electrical discharge machining. Archives of Materials Science and Engineering, 37 (2) 110-116. https://citeseerx.ist.psu.edu/viewdoc/download?doi=10.1.1.496.2083\&rep=rep1\&type=pdf

21. S. S. Mahapatra \& Amar Patnaik, Optimization of wire electrical discharge machining (WEDM) process parameters using Taguchi method, Int J Adv Manuf Technol (2007) 34:911-925. https://doi.org/10.1007/s00170-006-0672-6.

22. Yun YI, Park IY, Song SJ (2005) Performance Degradation due to Blade Surface Roughness in a Single-Stage Axial Turbine. ASME. J. Turbomach.127: 137-143. https://doi.org/10.1115/1.1811097.

23. Perumal A, Azhagurajan A, Prithivirajan R, Suresh Kumar S (2021) Experimental Investigation and Optimization of Process Parameters in $\mathrm{Ti}$ - (6242) Alpha-Beta Alloy Using Electrical Discharge Machining. Journal of Inorganic and Organometallic Polymers and Materials 31: 1787-1800 https://doi.org/10.1007/s10904-020-01786-1

24. Shather SK, Bin Sapit A, Nehad F (2021) Performance of Ti-6242 production using nano powder mixed with different dielectrics. Materials Today: Proceedings, 45: 4490-4497. https://doi.org/10.1016/j.matpr.2020.12.997.

25. Prasanna R, Kavimani V, Gopal PM, Simson D (2021) Multi-Response Optimization and Surface Integrity Characteristics of Wire Electric Discharge Machining a-Phase Ti-6242 Alloy. Process Integration and Optimization for Sustainability. https://doi.org/10.1007/s41660-021-00179-2.

26. Perumal A, Azhagurajan A, Kumar SS et al. (2021) Influence of Optimization Techniques on Wire Electrical Discharge Machining of Ti-6Al-2Sn-4Zr-2Mo Alloy using Modeling Approach. J Inorg Organomet Polym 31: 3272-3289. https://doi.org/10.1007/s10904021-01953-y.

27. Mandeep K, Hari S (2016) Multi response optimization in wire electrical discharge machining of Inconel X-750 using Taguchi's technique and grey relational analysis, Cogent Engineering, 3:1. https://doi.org/10.1080/23311916.2016.1266123.

28. Rao RV (2011) Modeling and Optimization of Modern Machining Processes. Advanced Modeling and Optimization of Manufacturing Processes, Springer Series in Advanced Manufacturing, London Limited. https://www.springer.com/gp/book/9780857290144\#reviews.

29. Chalisgaonkar R, Kumar J (2015) Multi-response optimization and modeling of trim cut WEDM operation of commercially pure titanium (CPTi) considering multiple user's performance. Engineering Science and Technology an International Journal 18:125-134. https://doi.org/10.1016/j.jestch.2014.10.006.

30. Ridgeon FJ, Raine MJ, Halliday DP, Lakrimi M, Thomas A, Hampshire, DP (2017) Superconducting properties of titanium alloys (Ti-64 and Ti-6242) for critical current barrels. IEEE transactions on applied superconductivity 27: 1-5. https://doi.org/10.1109/TASC.2016.2645378.

31. https://www.1stmachineryauctions.com/lots/charmilles-robofil-190-wire-eroder 1999? fbclid=IwAR3SA7IL1UTumleEBsiPmjM5C_IHiiOZyNmBTEqwwOGsz6XdkQtHAIOZsw0 (www.1stmachineryauctions.com, 21-8-2021)

32. Boulila A, Boujelbene M, Fekiri C., Hammami A (2019) Optimization of manufacturing complex-shaped gas turbine blades. Measurement, 135: 768-781. https://doi.org/10.1016/j.measurement.2018.12.040.

33. G.S. Peace, Taguchi Methods: A Hands-on Approach, Addison-Wesley, Reading, MA, 1993. 


\section{Figures}

a

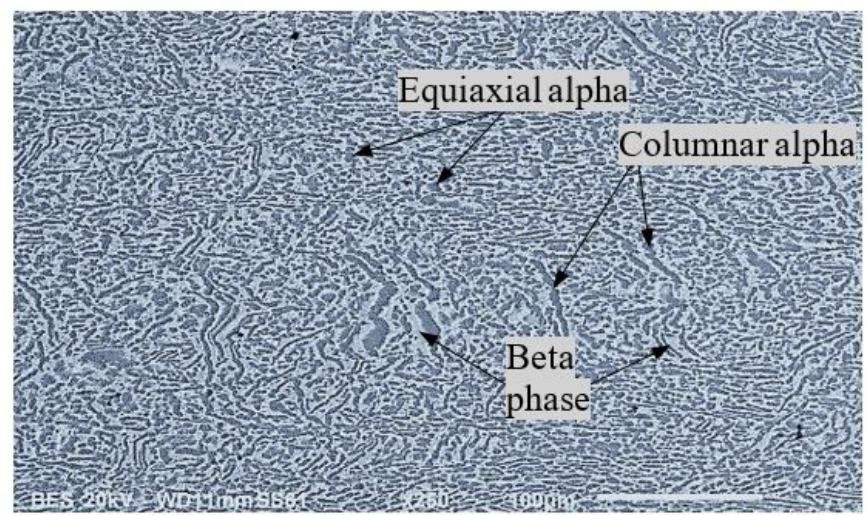

$\mathrm{b}$

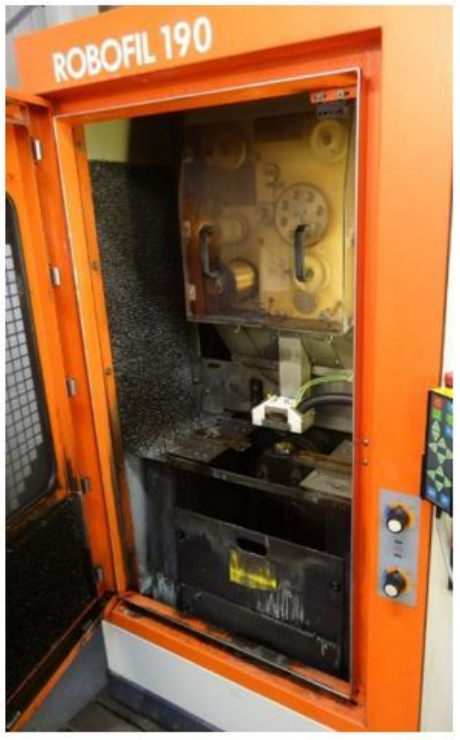

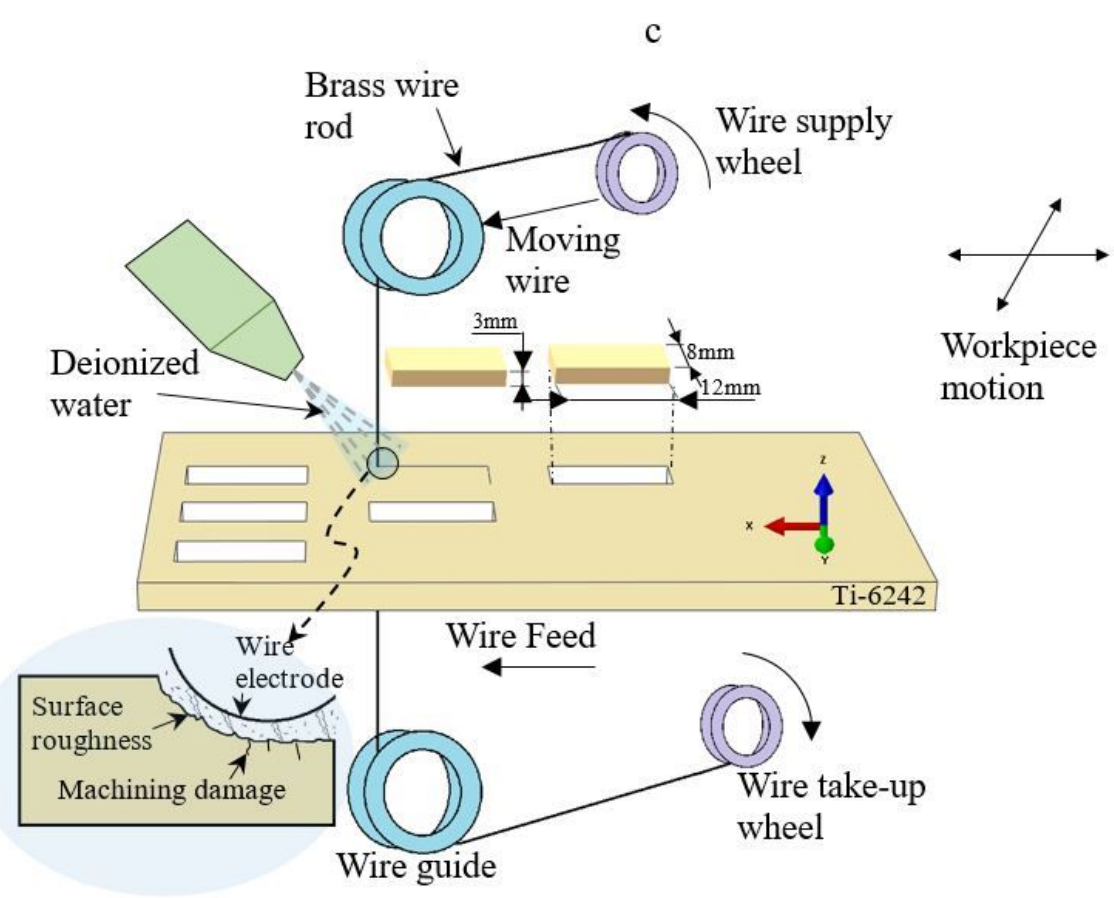

Figure 1

a- SEM observation of the microstructure of as-received Ti-6242 alloy, b- Robofil 190 CNC wire EDM machine used in cutting of Ti-6242 samples [31], c-Schematic diagram of WEDM of Ti-6242 samples for surface roughness investigation 


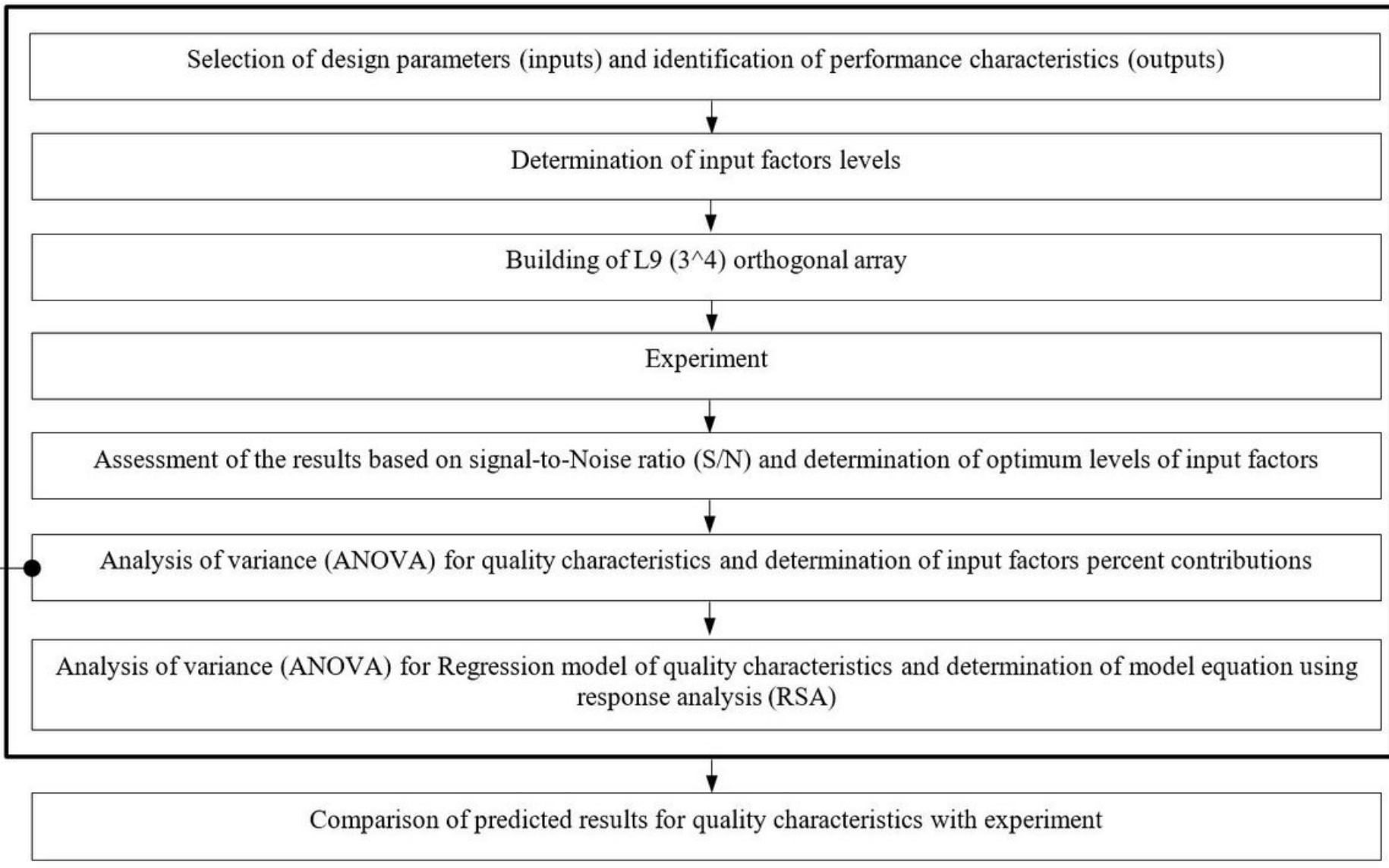

Evaluation of the effect of critical inputs parameters on the surface damage characteristics based on SEM examination of machined surface

Figure 2

Surface integrity assessment strategy pursued in present work

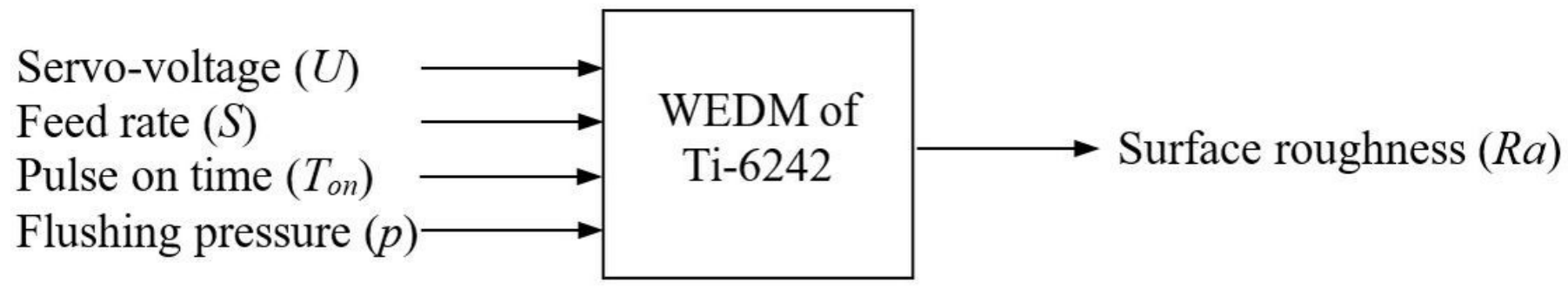

Figure 3

Input factors and performance characteristics in present study 


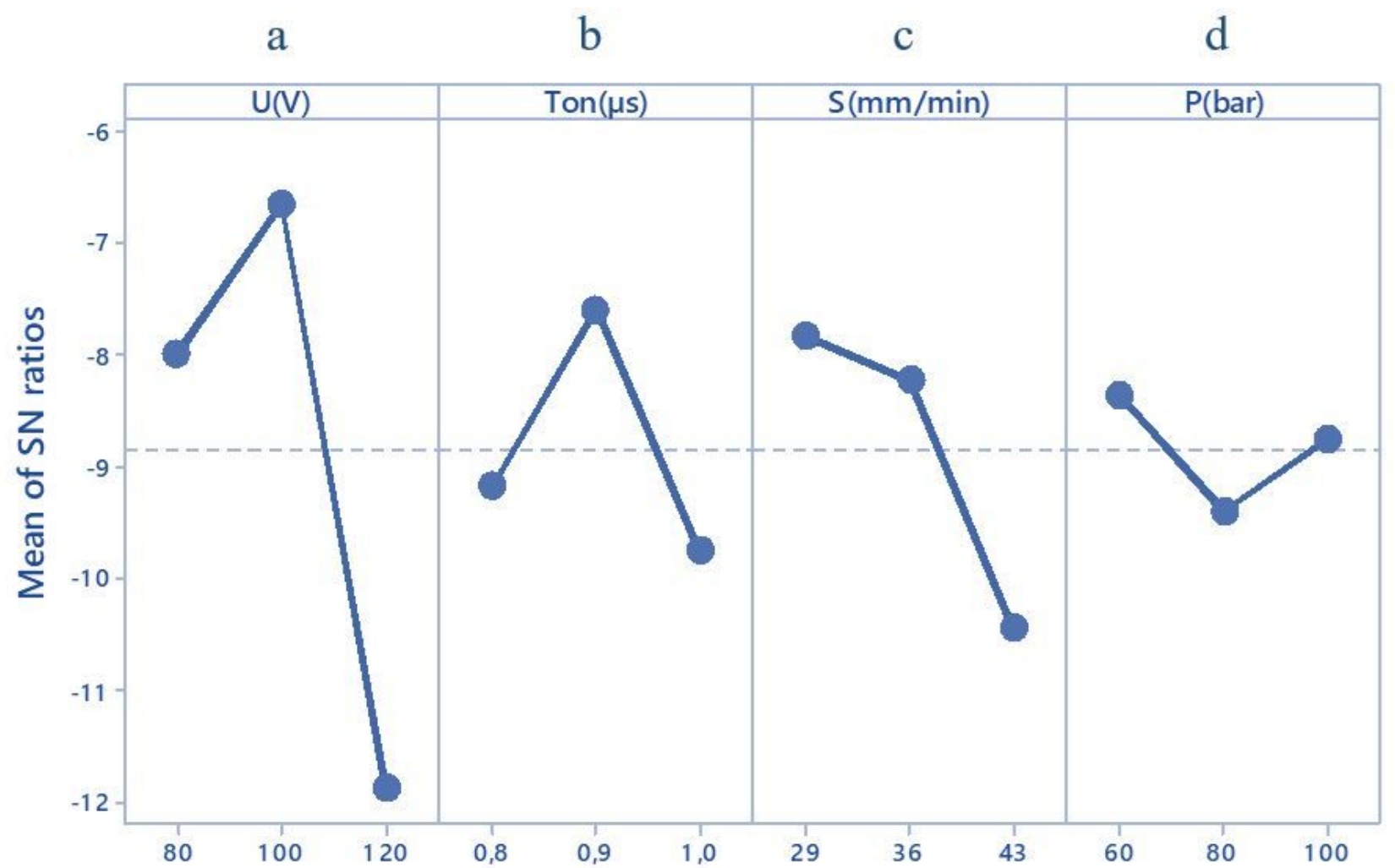

Signal-to-noise: Smaller is better

Figure 4

Main Effects plot for $\mathrm{SN}$ ratios on surface roughness $\mathrm{Ra}$

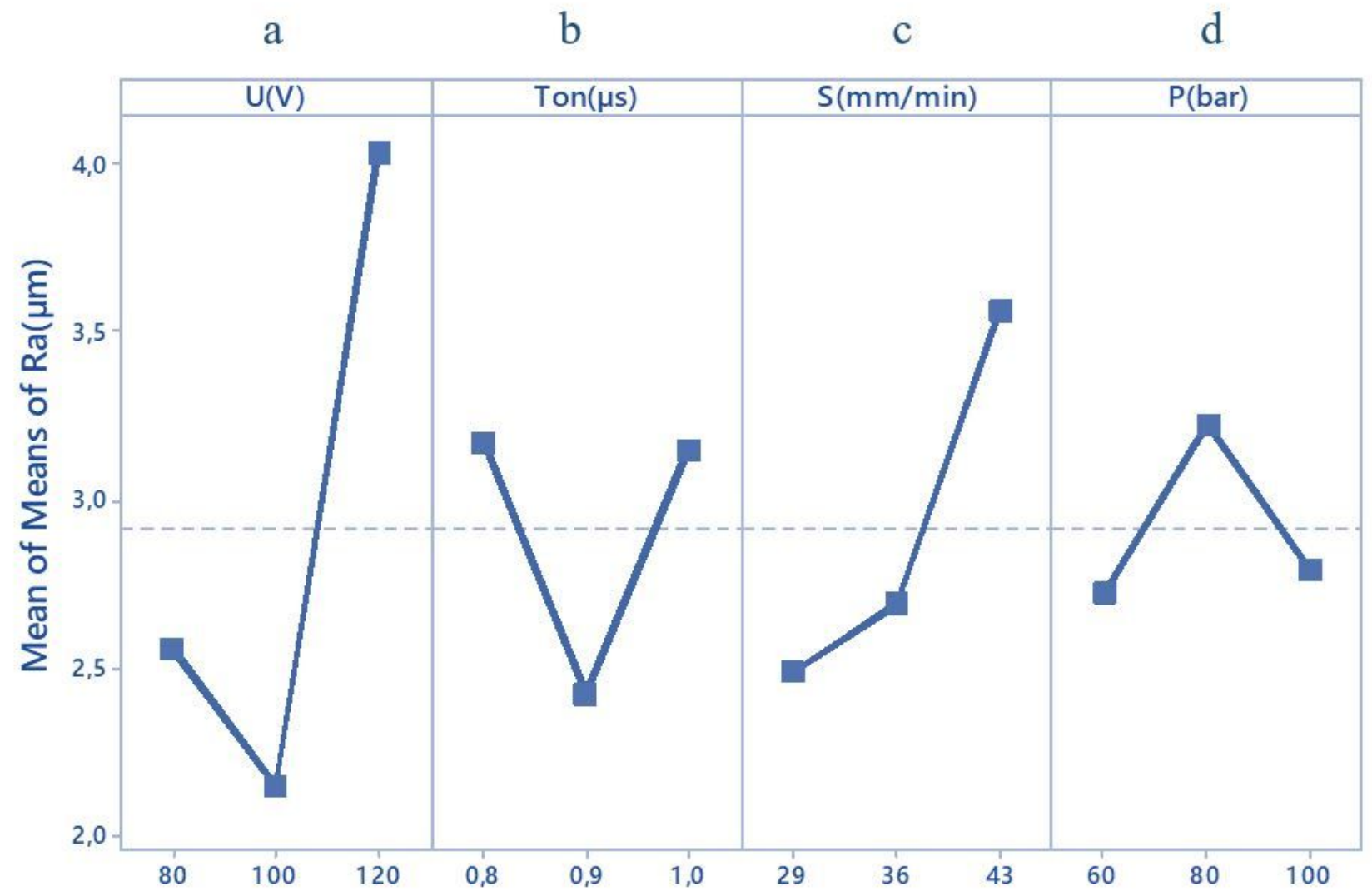

Page $16 / 23$ 


\section{Figure 5}

Main Effects plot for means on surface roughness Ra

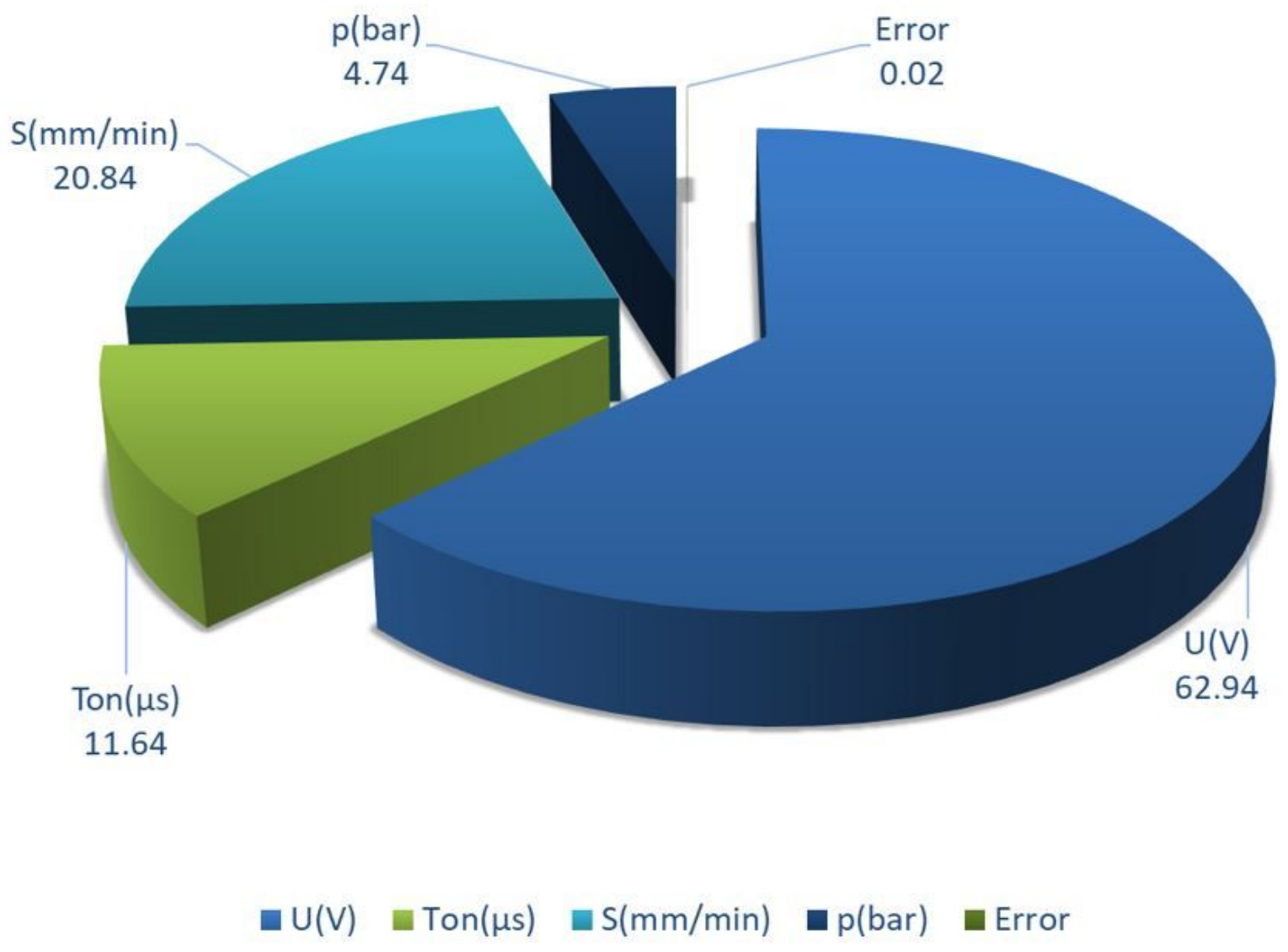

\section{Figure 6}

Percentage contribution of control factors for Ra. 

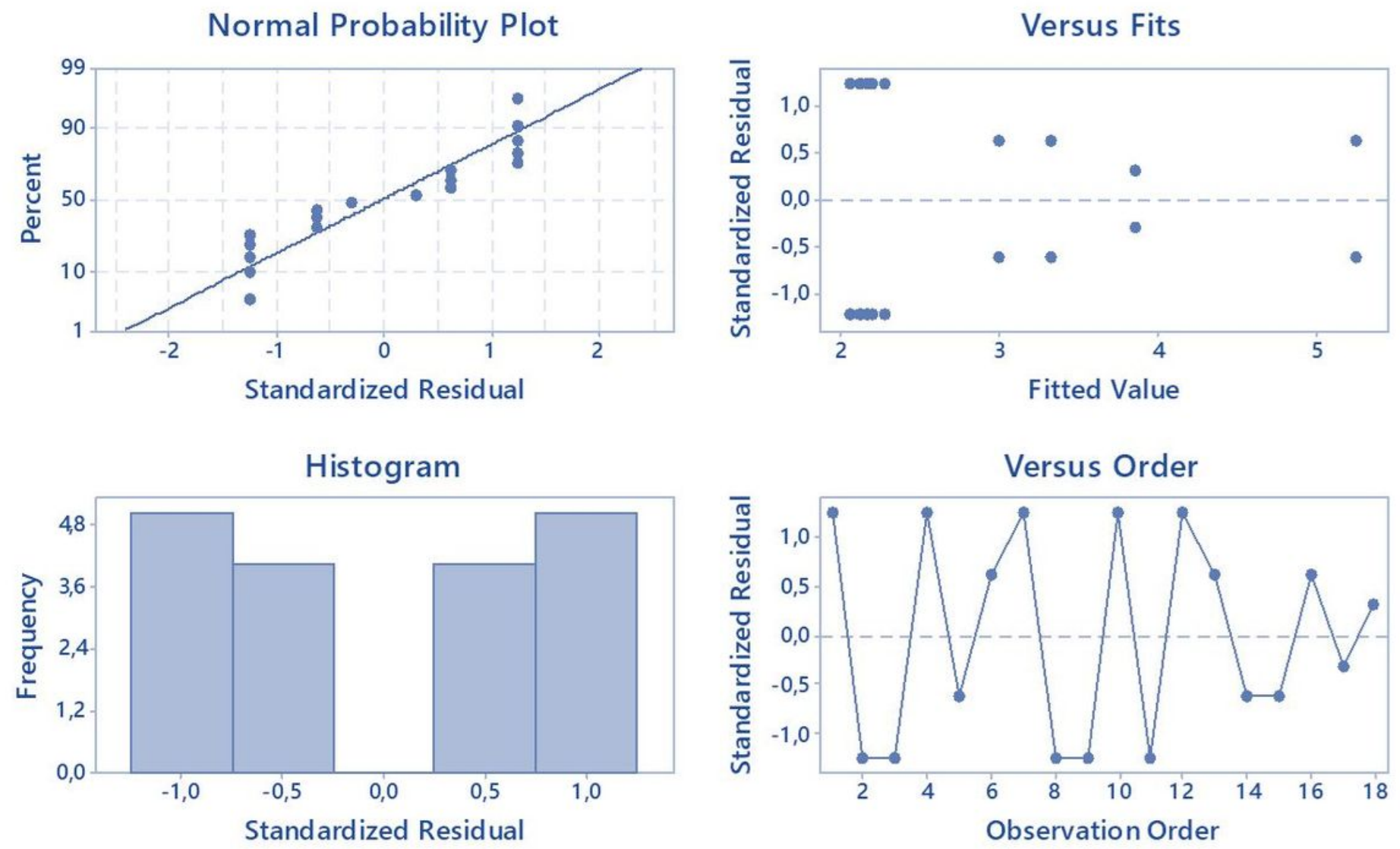

Figure 7

Residual plots for surface roughness $\mathrm{Ra}(\mu \mathrm{m})$.

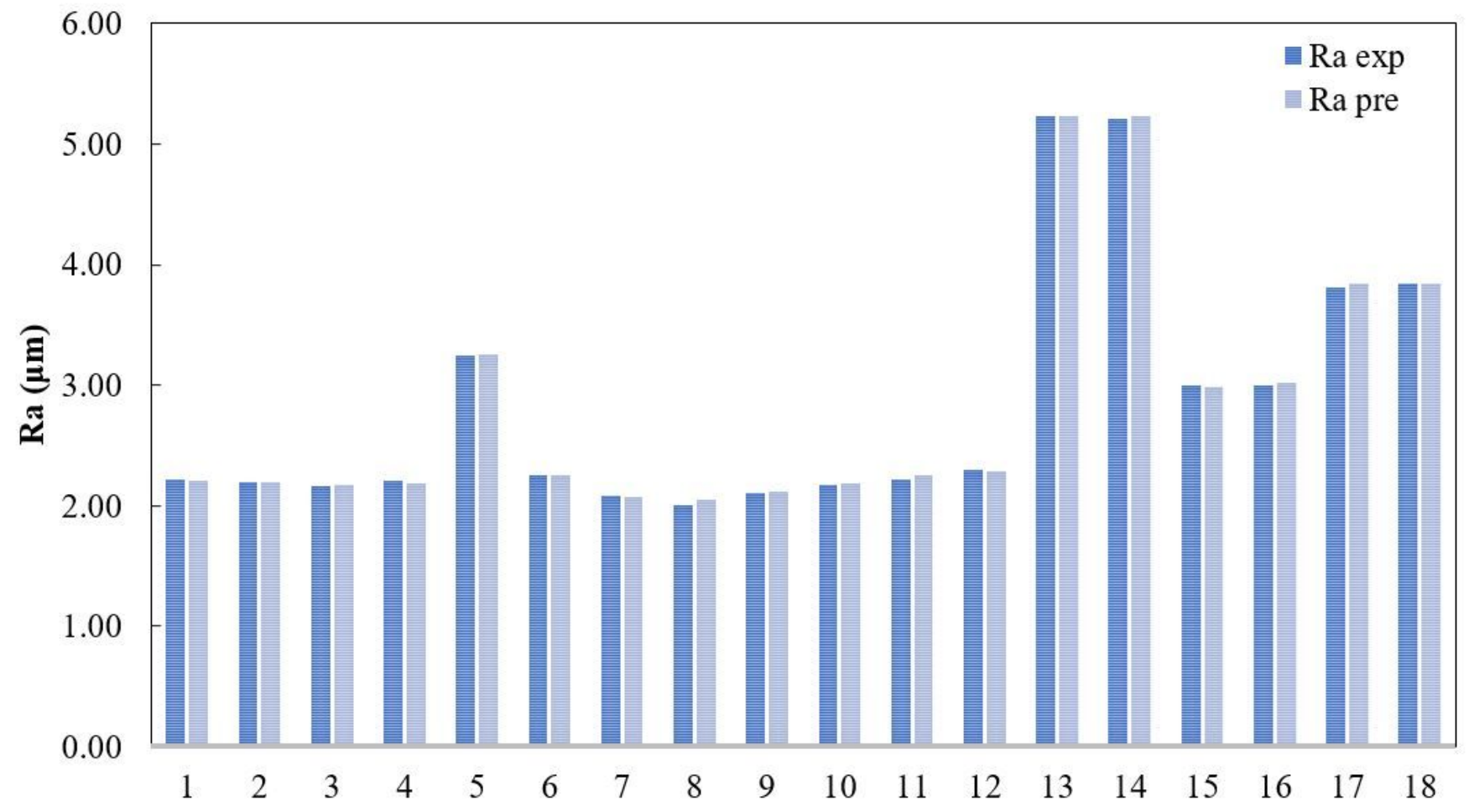




\section{Figure 8}

Comparison between measured and predicted values for Ra.

(a)

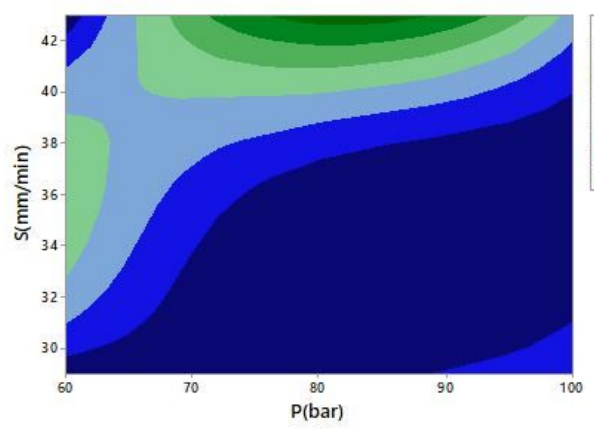

(c)

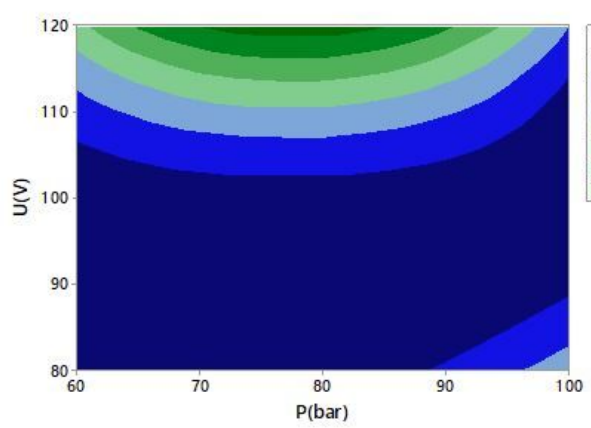

(e)

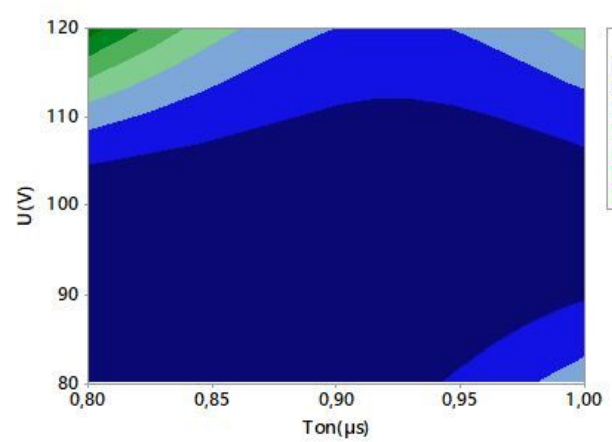

(b)

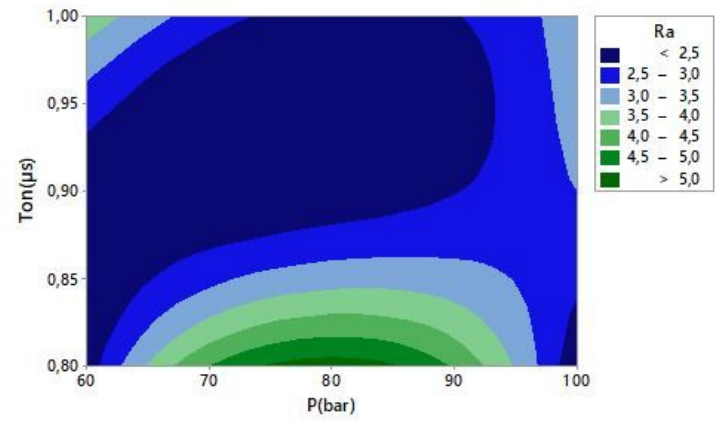

(d)

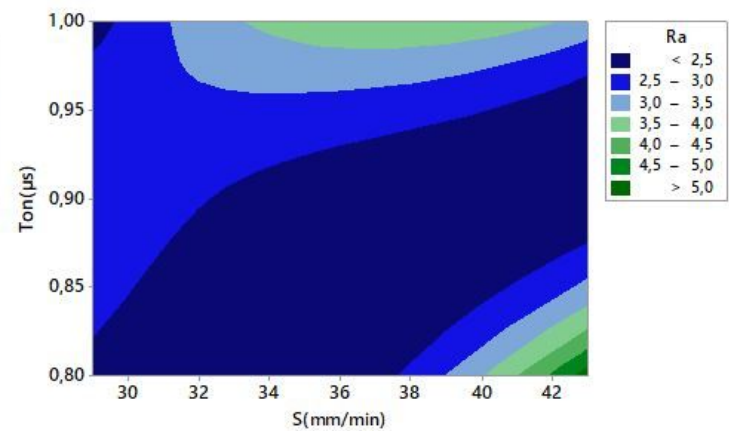

(f)

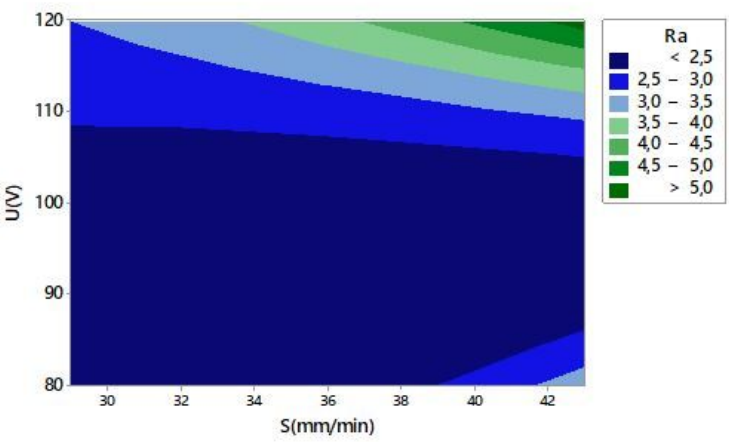

\section{Figure 9}

Contour plots of surface roughness Ra. 
(a)

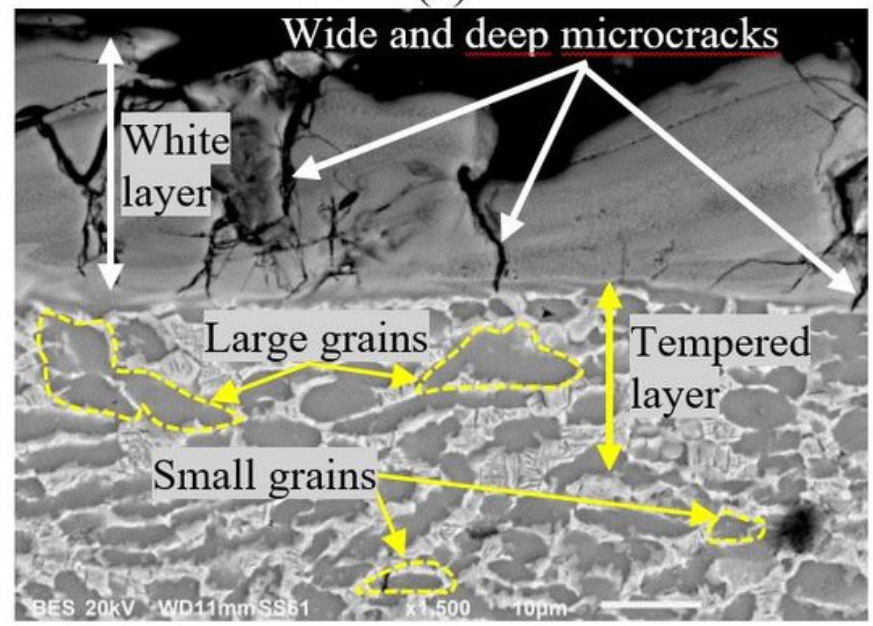

(b)

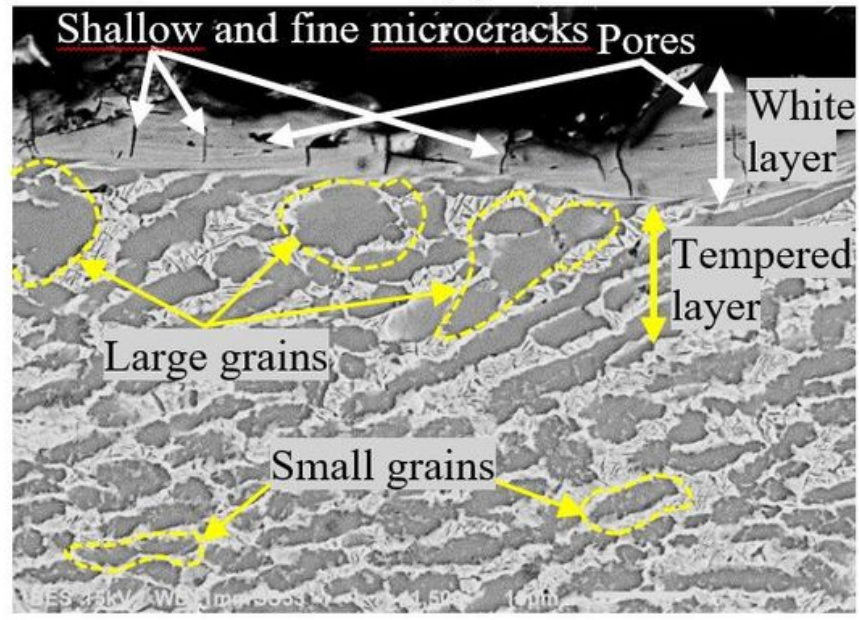

Figure 10

SEM micrograph of Ti-6242 machined surface obtained with WEDM process parameters (a) Set 1: U=80 V; Ton=1 $\mu$ s; $\mathrm{S}=43 \mathrm{~mm} / \mathrm{min}$; $P=100$ bar. (b) Set 2: U=120V; Ton=0.8 $\mu$; $S=43 \mathrm{~mm} / \mathrm{min}, \mathrm{P}=100$ bar (tool electrode material: brass, dielectric fluid: deionized water)

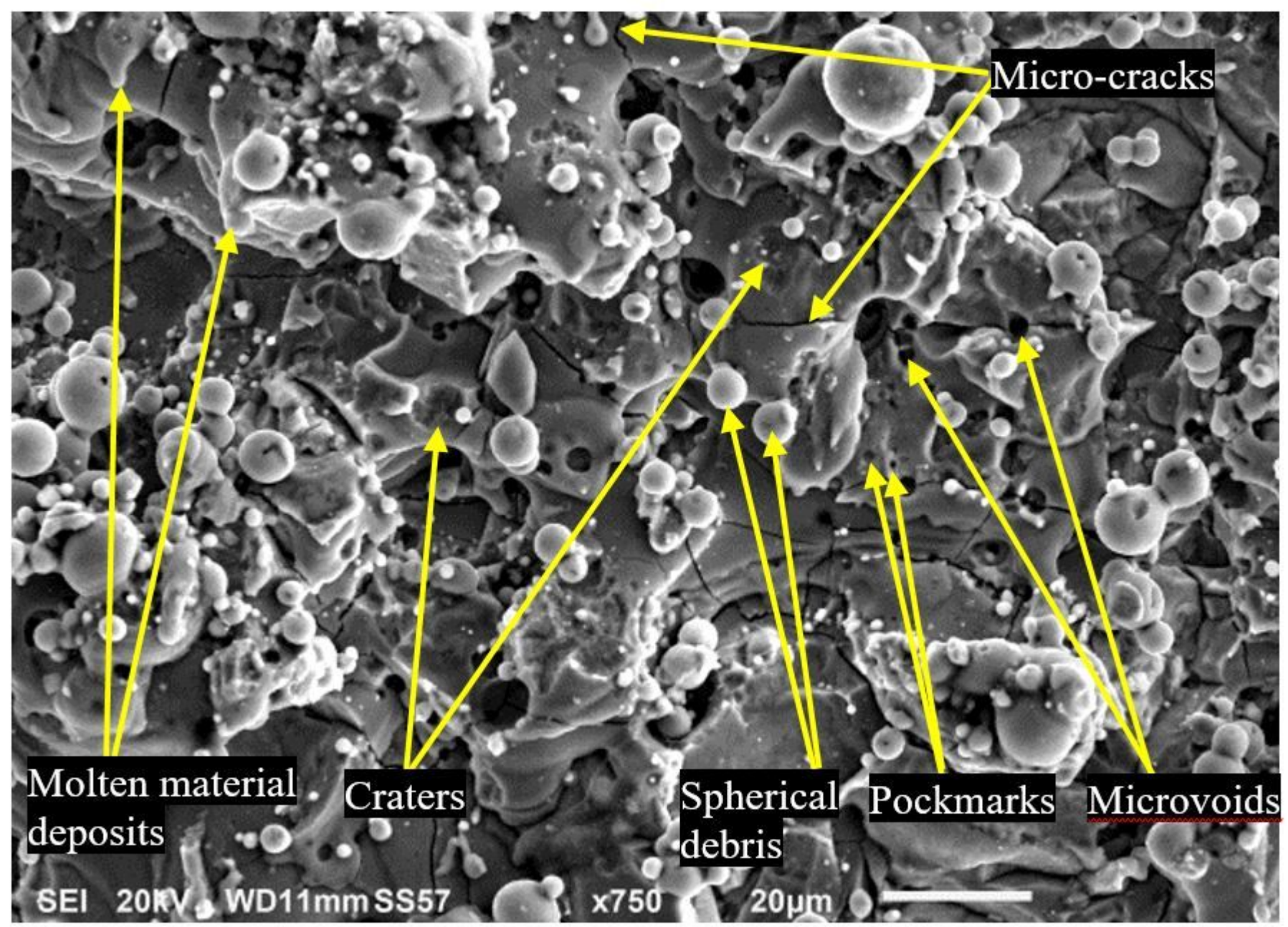

Figure 11

SEM micrograph of Ti-6242 machined surface obtained with WEDM process parameters (Set1- U=120V; S=36 mm $/ \mathrm{min}$; Ton= $1 \mu \mathrm{s}$; $\mathrm{P}=100 \mathrm{bar})$ 

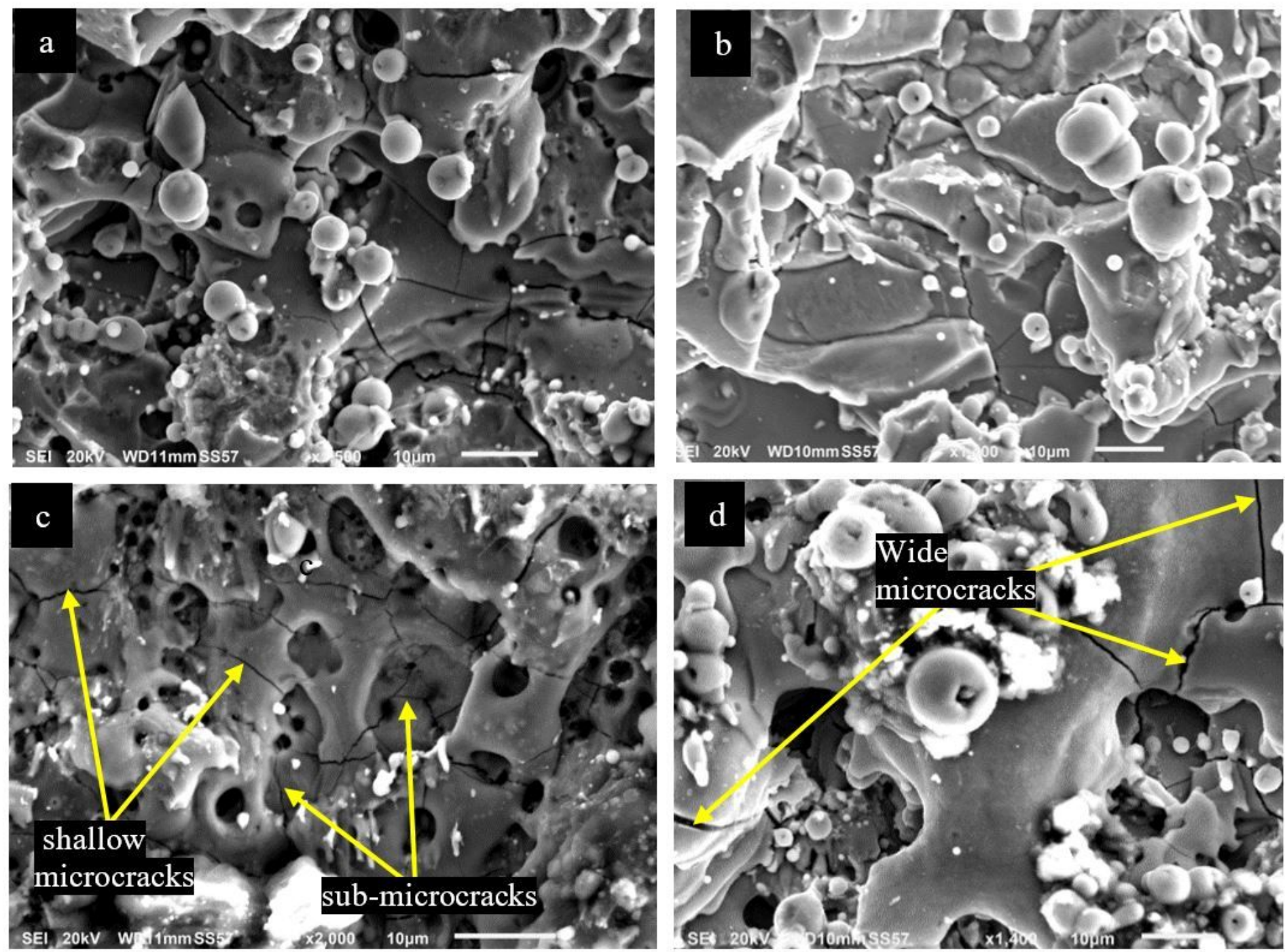

Figure 12

SEM micrographs of wire EDMed machined surface of Ti-6242 super alloy with combination sets (a-Set 1, b-Set 2, c-Set 3, d-Set 4) of machining parameters 


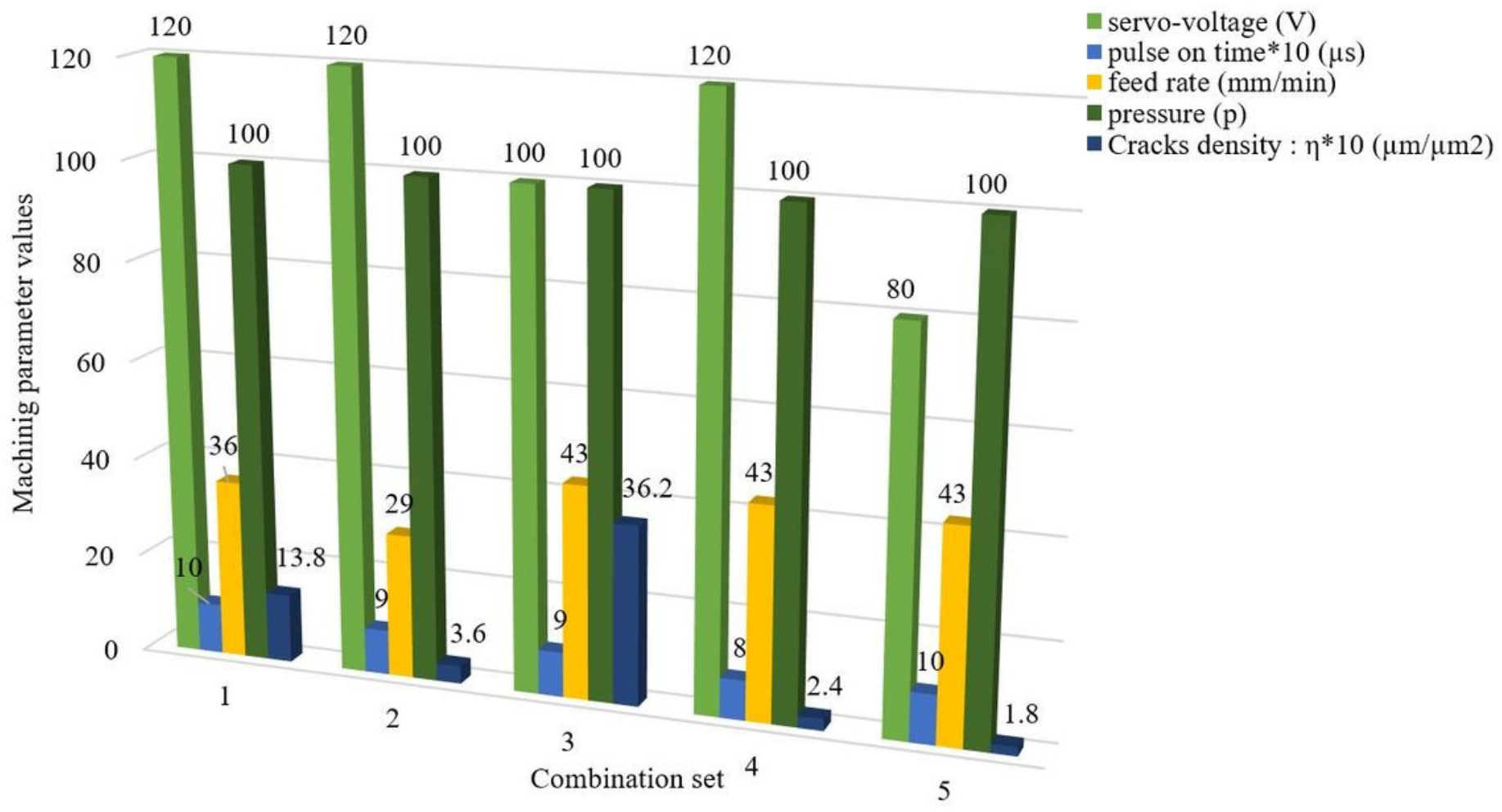

Figure 13

Variation of surface cracks density $\eta(\mu \mathrm{m} / \mu \mathrm{m} 2)$ with cutting conditions

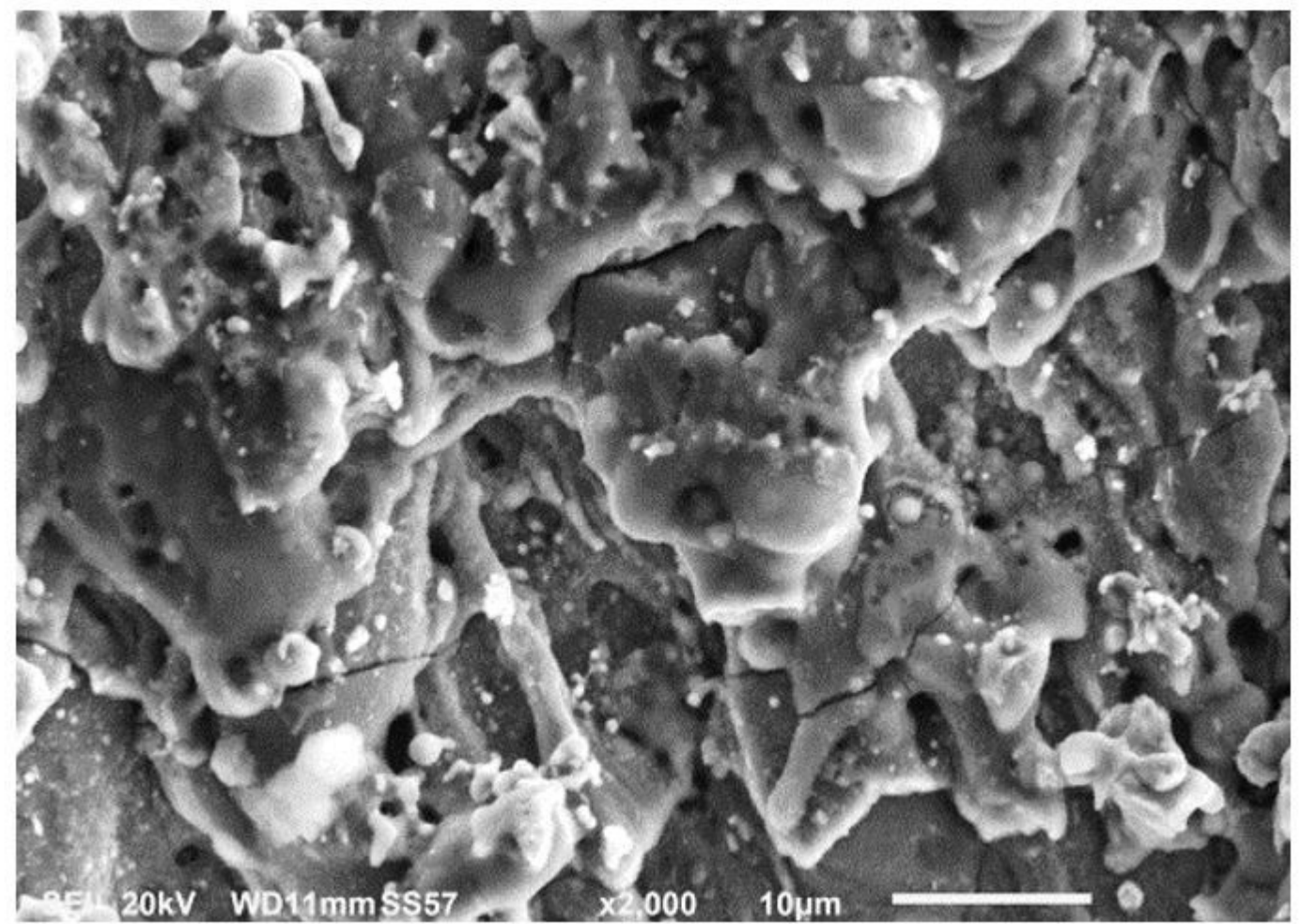

Figure 14 
SEM micrograph of wire EDMed machined surface of Ti-6242 super alloy with combination set $5(U=80 \mathrm{~V} ; \mathrm{S}=43 \mathrm{~mm} / \mathrm{min} ; \mathrm{Ton}=1 \mu \mathrm{s} ; \mathrm{p}=100$ bar) of machining parameters 